\title{
Análisis de procedencia del registro sin-orogénico Maastrichtiano de la Formación Cimarrona, flanco occidental de la Cordillera Oriental colombiana
}

\author{
Juan Camilo Valencia-Gómez ${ }^{1,2^{*}}$ (D) ; Agustín Cardona $^{2,3}$ (D) ; Germán Bayona ${ }^{4}$ (D) ; Víctor Valencia ${ }^{5}$ (D) ; \\ Sebastián Zapata ${ }^{6,7}$
}

Forma de citar: Valencia-Gómez, J.C.; Cardona, A.; Bayona, G.; Valencia, V.; Zapata, S. (2020). Análisis de procedencia del registro sin-orogénico Maastrichtiano de la Formación Cimarrona, flanco occidental de la Cordillera Oriental colombiana. Boletín de Geología, 42(3), 171-204. https://doi.org/10.18273/revbol.v42n3-2020008

\section{Resumen}

El registro clástico Maastrichtiano de la Formación Cimarrona en el flanco occidental de la Cordillera Oriental colombiana documenta la erosión de una topografía generada al occidente y asociada con el inicio de la orogenia Andina durante el Cretácico SuperiorPaleoceno, la cual suministró los sedimentos que se acumularon en ambientes continentales a transicionales. Los análisis de procedencia sedimentaria (conteo de clastos de conglomerados, petrografía, minerales pesados y geocronología detrítica U-Pb) en conjunto con los datos de paleocorrientes previamente publicados permiten reconstruir la historia del área fuente al occidente. Los circones detríticos con edades principalmente del Cretácico Superior, incluyendo un máximo de acumulación de $~ 66$ Ma, así como edades más limitadas del Pérmico (276 Ma), Triásico (246 Ma) y Jurásico (153 Ma), sugieren que la sedimentación estuvo asociada a un vulcanismo contemporáneo y a la erosión de rocas sedimentarias y cristalinas más antiguas. El alto contenido de cuarzo de las areniscas, junto con la asociación de líticos sugiere que el área de aporte incluía rocas sedimentarias clásticas, rocas metamórficas de bajo a muy bajo grado y rocas volcánicas félsicas a intermedias. El área de aporte consistía en coberturas volcano-sedimentarias Cretácicas suprayaciendo rocas del Jurásico y Permo-Triásico afín con los dominios litológicos y geocronológicos de la Cordillera Central. El carácter discontinuo del registro clástico grueso de la Formación Cimarrona sugiere que las áreas fuente eran bloques levantados discontinuos con valles intermedios, que probablemente se extendían hacia el este y ahora están enterrados debajo del relleno de la cuenca del Valle del Magdalena. El segmento de la Cordillera Central más compatible con estas características estaría al norte de la cuenca, apoyando la hipótesis de desplazamiento de rumbo post-Maastrichtiano de las áreas fuente al occidente.

Palabras clave: Análisis de procedencia; Formación Cimarrona; Cordillera Oriental; Maastrichtiano; Orogenia Andina.

\section{Provenance analysis of the Maastrichtian syn-orogenic record from the Cimarrona Formation, western flank of the Colombian Eastern Cordillera}

\begin{abstract}
The Maastrichtian clastic record of the Cimarrona Formation on the western flank of the Colombian Eastern Cordillera documents the erosion of a generated topography and is associated with the beginning of the Andean orogeny during the Late Cretaceous-Paleocene. Sedimentary provenance analyzes (conglomerate clast count, sandstone petrography, heavy minerals and U-Pb detrital geochronology) in conjunction with previously published paleocurrent data allow us to reconstruct the history of the source areas. Detrital zircons with ages primarily from the Upper Cretaceous, including a maximum accumulation of $\sim 66 \mathrm{Ma}$, as well as more limited ages from the Permian (276 Ma), Triassic (246 Ma), and Jurassic (153 Ma), suggest that sedimentation was associated to contemporary volcanism and to the erosion of older crystalline and sedimentary rocks. The high quartz content of the sandstones, together with the lithic association suggest that source rocks included clastic sedimentary rocks, low grade metamorphic rocks and felsic to intermediate volcanic rocks. The source area was characterized by a Cretaceous volcano-sedimentary cover sequence deposited on top of Jurassic and PermianTriassic basement rocks; this source area configuration resembles the present-day lithostratigraphic domains of the Central Cordillera. The discontinuous character of the coarse clastic record of the Cimarrona Formation suggests that the source areas were discontinuous uplifted blocks with valleys in between, these blocks likely extended eastwards and are now buried beneath the basin fill of the Magdalena Valley. The Central Cordillera segment that is most compatible with these characteristics is currently located north of the basin, suggesting that strike-slip tectonics was responsible for the northward displacement of the source areas after the Maastrichtian.
\end{abstract}

Keywords: Provenance analysis; Cimarrona Formation; Eastern Cordillera; Maastrichtian; Andean Orogeny.

\footnotetext{
${ }^{1}$ Departamento de Geociencias y Medio Ambiente, Universidad Nacional de Colombia, Medellín, Colombia. (*) juacvalenciagom@unal.edu.co

${ }^{2}$ Grupo de Investigación en Geología y Geofísica, Universidad Nacional de Colombia, Medellín, Colombia. agcardonamo@unal.edu.co ${ }^{3}$ Departamento de Procesos y Energía, Universidad Nacional de Colombia, Medellín, Colombia.

${ }^{4}$ Corporación Geológica Ares, Bogotá, Colombia. gbayona@cgares.org

${ }^{5}$ School of the Environment, Washington State University, Pullman, USA. victor.valencia@wsu.edu

${ }^{6}$ Smithsonian Tropical Research Institute, Panamá. szapatah@gmail.com

${ }^{7}$ Department of Geosciences and Geological and Petroleum Engineering, Missouri University of Science and Technology, Rolla, USA.
} 


\section{Introducción}

Los sistemas depositacionales que caracterizan una cuenca sedimentaria están controlados por la disponibilidad de sedimentos, la subsidencia tectónica, cambios en el nivel base y la proximidad de las áreas fuente. Así, durante su historia evolutiva, las cuencas sedimentarias pueden registrar cambios abruptos del nivel base de la cuenca; deformación sin-sedimentaria, caracterizada por presentar estratos de crecimiento; cambios faciales asociados a la historia de subsidencia; modificación de los volúmenes de sedimentación y de las áreas de aporte o procedencia de los sedimentos (DeCelles et al., 2011; Draut y Clift, 2012; Horton, 2018; Bayona, 2018).

La procedencia de secuencias clásticas asociadas a fases compresivas puede registrar la erosión progresiva de diferentes niveles estructurales en las áreas fuente (Dickinson y Suczek, 1979; Dorsey, 1988; Garzanti et al., 2004, 2007), así como cambios en las áreas de aporte asociados con desplazamientos horizontales a lo largo de sistemas de rumbo incluidos en el orógeno (Lamus-Ochoa et al., 2013; Zapata et al., 2014; Cheng et al., 2016; Montes et al., 2019).

Esta erosión progresiva, en conjunto con la variación temporal y espacial de las áreas que emergen durante la historia orogénica, puede tener como consecuencia, dependiendo de la magnitud de la erosión, la desaparición definitiva de las áreas fuentes del registro cartográfico, o eventualmente la preservación en el subsuelo al quedar cubiertas por los sedimentos posteriores.

En los Andes del Norte el inicio de las fases orogénicas que construyeron la cadena montañosa han sido documentadas evaluando los cambios ambientales del registro sedimentario expuesto en el oriente del país (Valle del Magdalena, Cordillera Oriental), donde entre el Coniaciano y el Paleoceno, ambientes depositacionales inicialmente marinos pasaron a ser transicionales y continentales, y las rocas clásticas se hacen progresivamente más inmaduras composicionalmente, caracterizándose por la aparición de material detrítico cuya procedencia tendría una relación con fuentes semejantes a las ubicadas al occidente, como el basamento de la Cordillera Central (Villamil, 1999; Guerrero et al., 2000; Gómez et al., 2003; Ayala et al., 2012; Nie et al., 2012; Caballero et al., 2013; Bayona, 2018).

Contemporáneamente a los ya mencionados cambios en las litofacies, al occidente del Valle del Magdalena, en las Cordilleras Central y Occidental (Figura 1) se ha documentado un incremento en las tasas de exhumación (Villagómez y Spikings, 2013), significativos cambios en la composición de las rocas magmáticas (Jaramillo et al., 2017), así como una importante sedimentación clástica al occidente caracterizada por fuentes mixtas de afinidad continental y oceánica (Pardo-Trujillo et al., 2020), los cuales también estarían relacionados con este inicio temprano de la orogenia Andina.

El comienzo de la orogenia Andina ha sido relacionado con la colisión oblicua y diacrónica, en dirección surnorte entre un dominio de afinidad oceánica (formado en latitudes más suroccidentales), y la margen continental Suramericana, cuyos remanentes acrecionados se encuentran actualmente en la Cordillera Occidental (Pindell et al., 1998, 2005; Villagómez et al., 2011; Spikings et al., 2015; Montes et al., 2019). Sin embargo, la historia de exhumación y deformación pudo comenzar más tempranamente, antes del Maastrichtiano, asociada a la historia de subducción del Cretácico Superior, que habría estado inicialmente marcada por el cierre de una cuenca de tras-arco formada en el Cretácico Inferior (Zapata et al., 2019; Cardona et al., 2020).

Las rocas clásticas del Maastrichtiano de la Formación Cimarrona, expuestas en el Valle Medio del Magdalena y en las estribaciones de la Cordillera Oriental (Figura 1), representan uno de los registros clásticos del Cretácico Superior (Gómez y Pedraza, 1994; Villamil, 1999; Gómez et al., 2003; Bayona, 2018), el cual documenta estas primeras fases compresivas en los Andes del Norte.

En esta contribución se presentan nuevos resultados petrográficos, análisis de minerales pesados y de geocronología detrítica de la Formación Cimarrona, obtenidos en muestras colectadas en la sección estratigráfica expuesta en la vía entre los municipios de Honda y Guaduas (Gómez y Pedraza, 1994; Figura 2), con el fin de documentar las áreas fuente de esta unidad.

Los resultados obtenidos sugieren que el área de aporte de la Formación Cimarrona correspondió a niveles estructurales más someros que los actualmente expuestos en la Cordillera Central, incluyendo las coberturas sedimentarias y volcánicas Cretácicas asociadas al extenso plutonismo de la misma edad. La posible afinidad de las características composicionales con las áreas fuente actualmente expuestas en un segmento más al norte de la Cordillera confirma la importancia de los desplazamientos de rumbo en la historia orogénica Cenozoica posterior. 


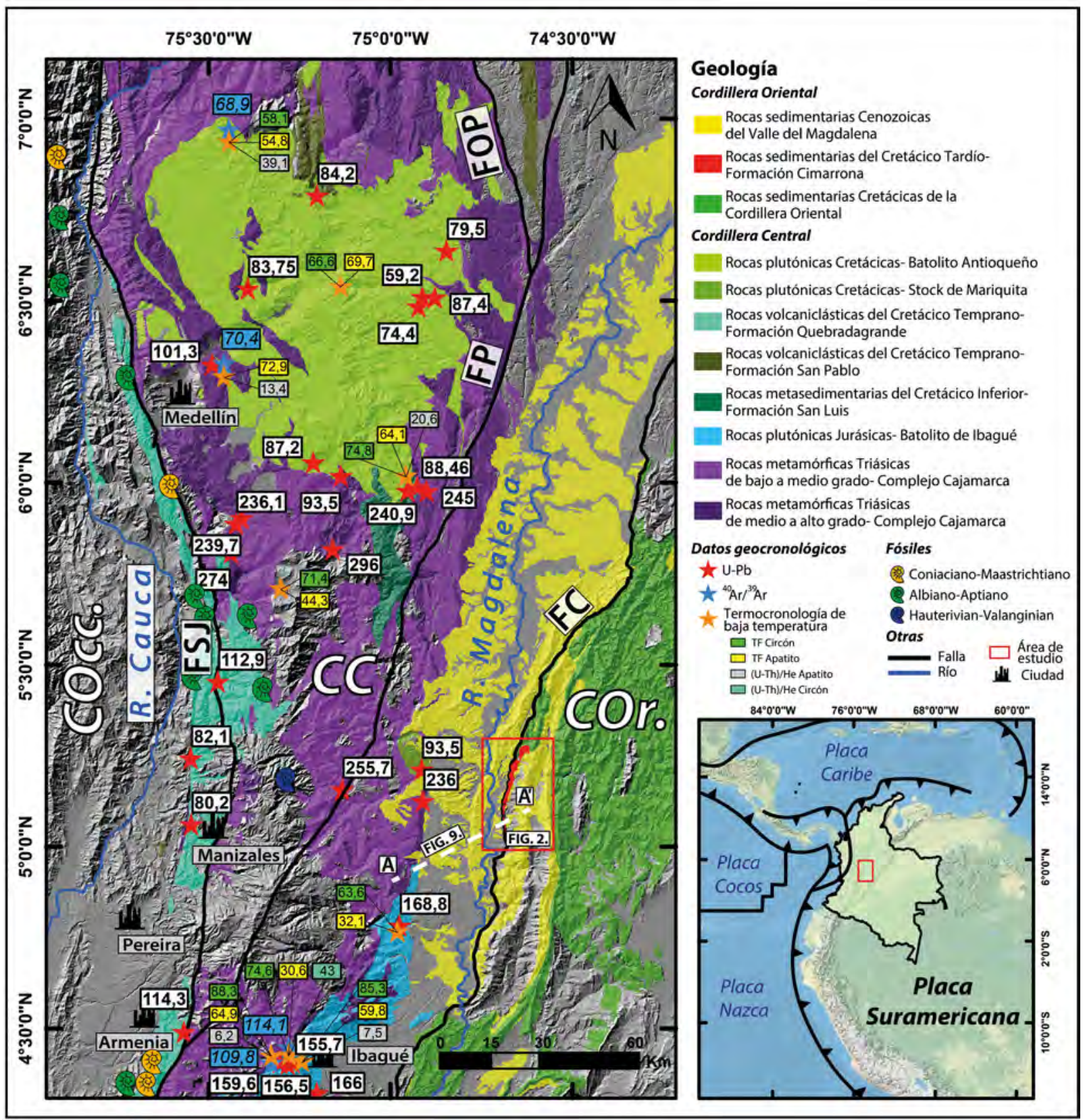

Figura 1. Mapa geológico regional de la Cordillera Central y el Valle Medio del Magdalena en los Andes colombianos incluyendo edades $\mathrm{U}-\mathrm{Pb}$ (estrellas rojas), edades Ar-Ar (estrellas azules) y edades termocronológicas de baja temperatura (estrellas naranjas) publicadas (Bustamante et al., 2010; Villagómez, 2010; Villagómez y Spikings, 2013; Restrepo-Moreno et al., 2009; Leal-Mejía, 2011; Cochrane, 2013; Villagómez et al., 2011; Ibáñez-Mejía et al., 2007). Las edades termocronológicas incluyen los métodos de trazas de fisión (TF) en circón (recuadros verdes), trazas de fisión (TF) en apatito (recuadros amarillos), (U-Th)/He en apatito (recuadros grises) y (U-Th)/He en circón (recuadros aguamarina). La zona de estudio está marcada por el recuadro rojo y la línea punteada blanca representa la ubicación del perfil esquemático A-A' de la Figura 9. FSJ: Falla San Jerónimo, FC: Falla Cambao, FP: Falla Palestina, FOP: Falla Otú-Pericos, CC: Cordillera Central, CO: Cordillera Oriental, COcc: Cordillera Occidental. 

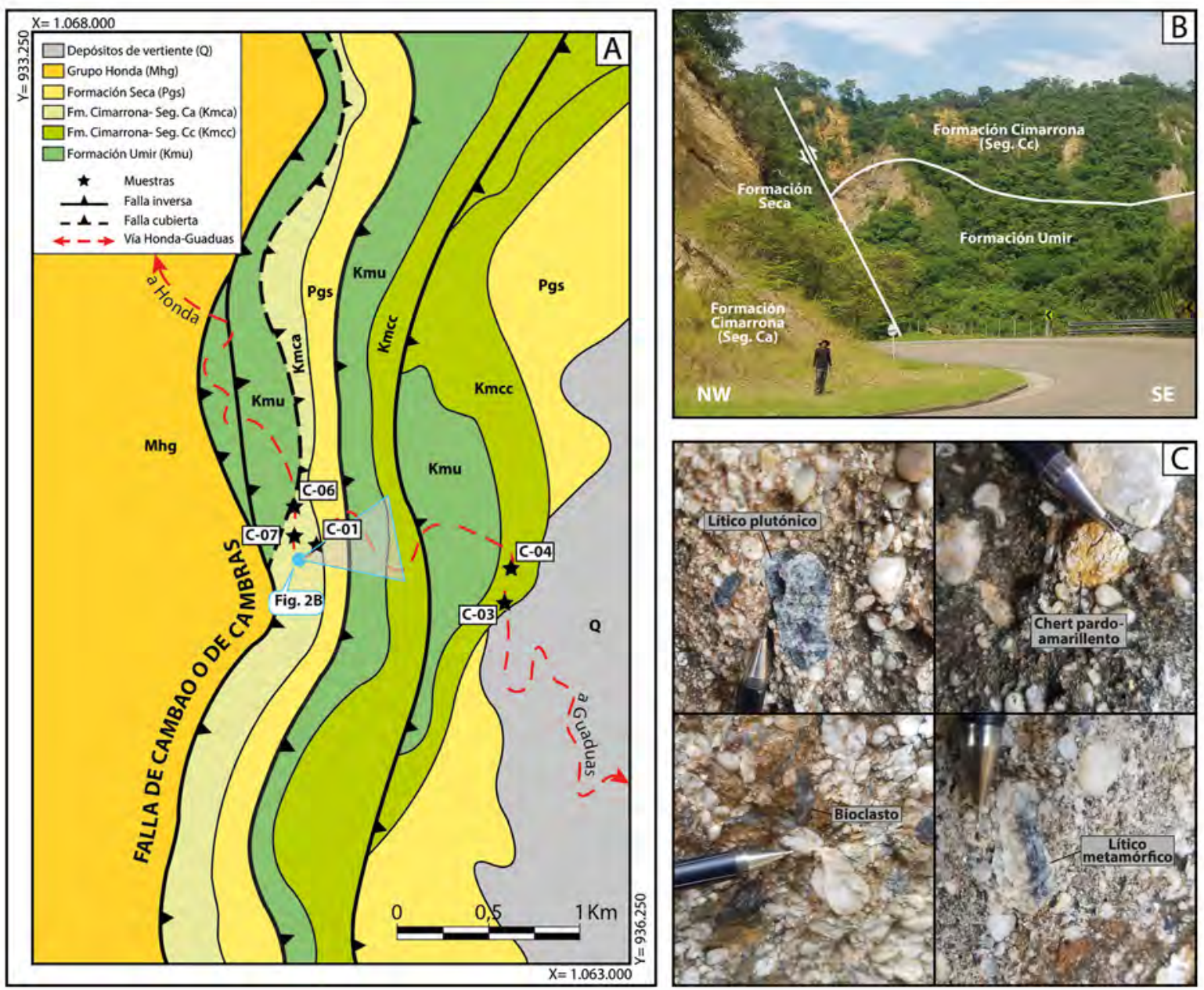

Figura 2. A. Mapa de la geología local de la zona de estudio modificado de Gómez y Pedraza (1994). B. Fotografía de las relaciones estratigráficas de las unidades en la zona de estudio. C. Fotografías de afloramientos donde se realizaron los conteos de conglomerados mostrando algunos tipos de clastos identificados. Las estrellas negras marcan la localización de las muestras colectadas. El punto azul y la zona triangular sombreada en el mapa marcan la posición donde fue tomada la fotografía en B y su área abarcada.

\section{Marco geológico}

Durante el Cretácico Inferior la margen continental de Suramérica se caracterizó por una historia geológica dominada por una tectónica extensional o de carácter neutral con limitada deformación (Gómez et al., 2003; Sarmiento-Rojas, 2006; Zapata et al., 2019), que en el Cretácico Superior se transformaría en una margen compresiva donde las condiciones de sedimentación y la historia magmática experimentaron profundas modificaciones, incluyendo la acreción de rocas oceánicas al occidente (Kerr et al., 1997; Pindell et al., 1998, 2005; Villagómez et al., 2011; Spikings et al., 2015; Bayona, 2018; Horton, 2018; Zapata et al., 2019; Cardona et al., 2020; Montes et al., 2019).
En los Andes colombianos, es posible reconocer en las tres cordilleras y los valles intramontanos que las separan (Magdalena y Cauca) diferentes remanentes de esta compleja historia geológica. La Cordillera Oriental y el Valle del Magdalena exponen un registro del Cretácico, caracterizado por unidades sedimentarias acumuladas en fondos marinos someros que favorecieron la acumulación de extensos depósitos de shales negros, calizas y chert (Etayo et al., 1976; Villamil, 1999; Elrich et al., 2003), los cuales se acumularon sobre una secuencia clástica y carbonatada relacionada con una historia extensional previa que modificó el borde continental durante el Jurásico Superior y el Cretácico Inferior (Sarmiento-Rojas et al., 2006; Mora et al., 2009). Estas condiciones de 
acumulación, dominadas por una subsidencia termal, relacionadas con una fase de tectónica más tranquila, cambiaron en el Cretácico Superior-Paleoceno, cuando los ambientes de acumulación registraron condiciones regresivas, marcadas por acumulaciones en ambientes de plataforma marina (e.g. Formación Umir), ambientes marginales de tipo abanico deltaico (e.g. Formación Cimarrona) y ambientes continentales caracterizados por sistemas de canales sinuosos someros (e.g. Formación Seca), los cuales documentan el inicio de la emergencia de los Andes en Colombia desde el Campaniano Temprano (Gómez et al., 2003; Bayona, 2018).

Este extenso registro Cretácico se acumuló sobre un sustrato asociado a la erosión diferencial en bloques de semi-grábenes y formado por rocas sedimentarias Paleozoicas y Mesozoicas, así como un basamento ígneo y metamórfico del Paleozoico Inferior. En los extremos norte y sur de la Cordillera Oriental, el sustrato incluye igualmente rocas Jurásicas plutónicas, además de importantes exposiciones del Precámbrico (Cordani et al., 2005; Ibañez-Mejia et al., 2011; Mantilla-Figueroa et al., 2013; Cardona et al., 2016; Van der Lelij et al., 2016).

La Cordillera Central y el segmento occidental del Valle del Magdalena se caracterizan por la presencia de basamento plutónico y metamórfico de edad Pérmica y Triásica, con edades entre 236 Ma y 277 Ma (Villagómez et al., 2011; Cochrane et al., 2014a; Spikings et al., 2015; Bustamante et al., 2017; Rodríguez-García et al., 2019; Figura 1), así como algunos remanentes escasamente expuestos de rocas ígneas Carboníferas (Leal-Mejía et al., 2019). Una extensa serie de rocas volcánicas y plutónicas Jurásicas, con edades entre 190 Ma y 142 Ma, se encuentra ampliamente expuesta en el flanco oriental de la Cordillera Central y también en los valles Medio y Superior del Magdalena. Además rocas metamórficas de bajo a medio grado con circones detríticos con edades jurásicas, de entre 163 y 193 Ma, formadas a partir de rocas volcano-sedimentarias, ocurren en el flanco oriental de la Cordillera Central (Bustamante et al., 2010, 2016, 2017; Leal-Mejía, 2011; Villagómez et al., 2011; Blanco-Quintero et al., 2014; Cochrane et al., 2014b; Naranjo et al., 2018). El registro sedimentario Cretácico incluye una serie de secuencias clásticas transicionales y marinas del Cretácico Inferior (e.g. Sedimentitas de San Luis, Berlín, Amalfi, Formaciones Abejorral y Valle Alto), las cuales en conjunto con algunos remanentes de rocas volcánicas tales como el Complejo Quebradagrande y la Formación San Pablo se encuentran expuestas de forma discontinua en la zona axial y en ambos flancos de la Cordillera (Figura 1), y estarían caracterizadas por un metamorfismo de muy bajo grado, frecuentemente relacionado con zonas de falla asociadas a una deformación del Cretácico Superior (Nivia et al., 2006; Villagómez et al., 2011; Rodríguez y Cetina, 2016; Jaramillo et al., 2017; Rodríguez-García y Celada-Arango, 2018; AvellanedaJiménez et al., 2020; Cardona et al., 2020; Zapata et al., 2019). Una serie de cuerpos ígneos plutónicos de composición granodiorítica a tonalítica con afinidad de arco magmático y edades entre $98 \mathrm{Ma}$ y $58 \mathrm{Ma}$, dentro de los que se destaca el Batolito Antioqueño, intruyen el basamento más antiguo y las unidades Cretácicas (Ordóñez-Carmona y Pimentel, 2001; Ibáñez-Mejía et al., 2007; Villagómez et al., 2011; Duque-Trujillo et al., 2019; Leal-Mejía et al., 2019; Cardona et al., 2020; Figura 1).

Aunque el plutonismo Cretácico se encuentra ampliamente distribuido en la Cordillera Central, las rocas volcánicas asociadas a este no han sido reconocidas, pese a que, al oriente, en el Valle del Magdalena y la Cordillera Oriental, se han identificado algunos niveles de cenizas volcánicas intercaladas con las secuencias sedimentarias acumuladas en los ambientes de plataforma (Villamil y Arango, 1998; Villamil, 1999; Terraza-Melo, 2012; Ballesteros-Torres et al., 2013).

En la Cordillera Occidental se exponen rocas volcánicas y plutónicas de composición máfica a intermedia y sedimentos marinos del Cretácico Inferior a Superior, con edades comprendidas entre 78 Ma y 100 Ma, las cuales se formaron en ambientes oceánicos con afinidad de plateau y arco oceánico (Toussaint y Restrepo, 1994; Kerr et al., 1997; Pindell et al., 2005; Villagómez et al., 2011; Rodríguez y Arango, 2013; Weber et al., 2015; Zapata-Villada et al., 2017). Estas rocas están asociadas a la placa del Caribe, la cual se formó en el Pacífico en latitudes más suroccidentales (Pindell y Kennan, 2009; Boschman et al., 2014; Hincapié-Gómez et al., 2018), e interactuó con el borde continental del norte de Suramérica durante el Cretácico Superior dejando remanentes acrecionados en el borde continental y ocasionando altas tasas de exhumación tanto en la Cordillera Central como en la Occidental (Villagómez y Spikings, 2013; Pindell y Kennan, 2009; Montes et al., 2019). Una extensa cobertera siliciclástica acumulada en ambientes turbidíticos con procedencia mixta continental y oceánica cubre los dominios acrecionados y restringe también los eventos colisionales al Cretácico Superior (Pardo-Trujillo et al., 2020). 


\section{Marco estratigráfico}

El registro sedimentológico en la porción occidental de la Cordillera Oriental y el Valle del Magdalena (e.g. Formación Cimarrona, Formación La Tabla), entre las latitudes $4,5^{\circ} \mathrm{N}$ y $5,5^{\circ} \mathrm{N}$, marca el cambio de ambientes de acumulación en plataforma marina en el Cretácico Superior (e.g. Formación Umir; De Porta, 1965, 1966; Gómez y Pedraza, 1994), a ambientes transicionales de tipo deltaico Maastrichtianos (e.g. formaciones Cimarrona y La Tabla; De Porta, 1965, 1966; Gómez y Pedraza, 1994; Guerrero et al., 2000; Montes et al., 2005), y que finalizaría con unidades acumuladas en ambientes típicamente continentales desde el Paleoceno (e.g. Formación Seca; Gómez y Pedraza, 1994). La sedimentación registrada por estas formaciones reemplaza ambientes marinos de plataforma tranquila, desarrollados previamente; además las facies sedimentarias a nivel regional señalan el cambio de ambientes marinos a ambientes continentales, registrando la generación de una topografía al occidente relacionada a una ancestral Cordillera marginal y una serie de altos intraplaca (Bayona, 2018).

La Formación Cimarrona redefinida por Gómez y Pedraza (1994) aflora en la vía Honda-Guaduas (Departamento de Cundinamarca), en el flanco occidental del Sinclinal de Guaduas, en el piedemonte occidental de la Cordillera Oriental. Esta unidad está expuesta en una serie de escamas tectónicas repetidas (Figura 2) que culminan en la parte inferior en contacto fallado inverso con rocas del Mioceno del Grupo Honda, marcando la historia deformacional postMiocena del flanco oriental de la Cordillera Oriental (Gómez et al., 2003; Cortés et al., 2006).

Gómez y Pedraza (1994) relacionan esta formación con los paquetes conglomeráticos descritos por De Porta (1966), dividiéndola en segmento Ca y segmento $\mathrm{Cc}$, correspondientes a los miembros Primavera y La Fría, los cuales representarían variaciones laterales del sistema depositacional. Las relaciones de campo (Figura 2B), muestran que el segmento $\mathrm{Cc}$ y la subyacente Formación Umir están en contacto fallado con la Formación Seca, la cual reposa concordantemente sobre el segmento $\mathrm{Ca}$, lo cual coincide con la variación lateral del sistema depositacional que representan el segmento $\mathrm{Ca}$ y $\mathrm{Cc}$ sugerida en trabajos anteriores (Gómez y Pedraza, 1994).

Las rocas infrayacentes y suprayacentes a la Formación Cimarrona corresponden a las lodolitas calcáreas bioturbadas y areniscas de la Formación Umir, y a areniscas y lodolitas cuarzosas de la Formación Seca respectivamente.

Litoestratigráficamente esta unidad corresponde a conglomerados masivos cuarzosos intercalados con areniscas conglomeráticas y ocasionalmente lodolitas y calizas (Figura 3), cuya diferencia principal está dada por la mayor abundancia de conglomerados en el segmento Cc. La infrayacente Formación Umir incluye lodolitas calcáreas terrígenas bioturbadas de color café claro con abundante contenido fósil que se intercalan con areniscas hacia el techo (Gómez y Pedraza, 1994).

Análisis paleontológicos incluyendo foraminíferos y ostrácodos recolectados en el segmento Cc, el segmento $\mathrm{Ca}$ y la infrayacente Formación Umir sugieren una edad de acumulación del Maastrichtiano para esta unidad (De Porta (1966) en Gómez y Pedraza (1994); Tchegliakova, (1996)). El análisis de facies la relaciona con un ambiente fluvial de corrientes trenzadas de baja sinuosidad que dominan en el segmento Ca y otros que se generaron en un ambiente submarino que representa barras de desembocadura y de frente deltaico que predominan en el segmento Cc (Gómez y Pedraza, 1994), que en conjunto estarían asociados a sistemas de abanicos deltaicos.

Gómez y Pedraza (1994) a partir de análisis de paleocorrientes y la presencia de gravas de carácter metamórfico en los conglomerados señalan un área fuente de los sedimentos ubicada al occidente, la cual estaría relacionada probablemente con una ancestral Cordillera Central (Bayona, 2018). 


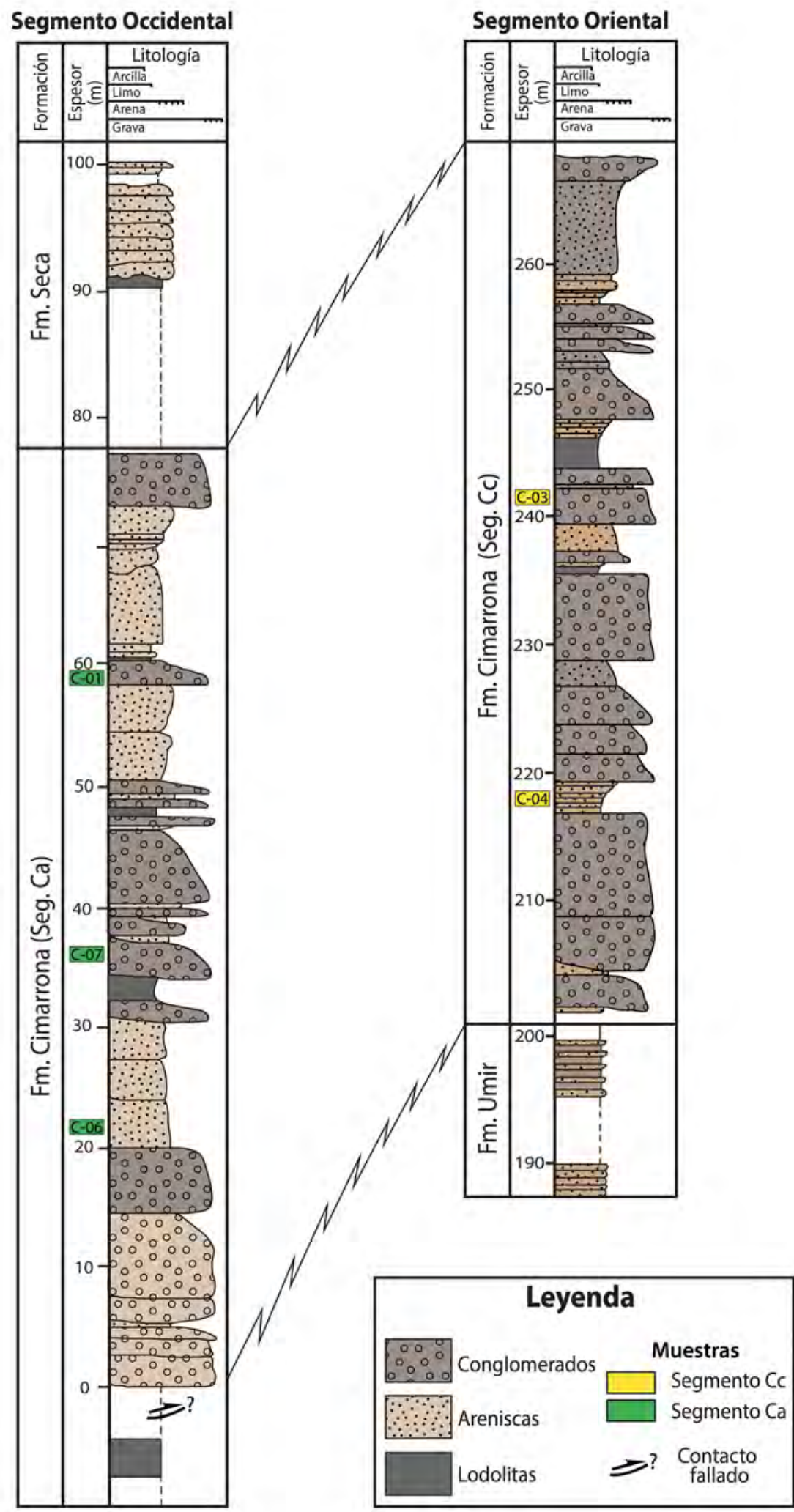

Figura 3. Columna estratigráfica de la Formación Cimarrona presentada por Gómez y Pedraza (1994). Las muestras del segmento $\mathrm{Ca}$ (recuadros verdes) y segmento Cc (recuadros amarillos) de este trabajo se localizan en la columna estratigráfica. 


\section{Metodología}

Para el análisis integrado de procedencia fueron realizados conteo de clastos de conglomerados (uno por segmento), análisis petrográficos (5 muestras), conteo de minerales pesados ( 3 muestras) y geocronología detrítica U-Pb en circón (1 muestra). A continuación, se describen los diferentes métodos mencionados.

\section{Conteo de clastos de conglomerados}

Se realizaron dos conteos de conglomerados, uno en el segmento Ca y otro en el segmento Cc, descritos por Gómez y Pedraza (1994). Una malla de un metro por un metro dividida cada $10 \mathrm{~cm}$ fue usada para realizar los conteos de conglomerados, obteniendo un total de 100 puntos, los cuales se identificaron composicionalmente usando una lupa de campo.

\section{Petrografía}

Cinco secciones delgadas fueron analizadas, siguiendo el método convencional (Suttner et al., 1981) que incluye la identificación de tipos de granos, texturas características y material intersticial (cemento, matriz y poros), a partir del conteo de 250 granos mediante el método propuesto por Gazzi-Dickinson para eliminar dificultades composicionales relacionadas con el tamaño de grano (Dickinson, 1970; Ingersoll et al., 1984). Además, se realizó una discriminación detallada de fragmentos líticos, en la cual se diferenciaron los tipos de líticos sedimentarios, líticos metamórficos según las categorías propuestas por Garzanti y Vezzoli (2003) y líticos volcánicos según las categorías propuestas por Dickinson (1970), incluyendo la diferenciación de los tipos de cuarzo monocristalino y policristalino (Basu et al., 1975).

\section{Minerales pesados}

La preparación de las muestras para el estudio de los minerales pesados incluyó la pulverización manual de la roca y tamizado por malla $400 \mu \mathrm{m}$. Para concentrar los minerales pesados se realiza un bateo manual y posteriormente una separación por densidad mediante el uso de politungstato de sodio con una densidad de $2,89 \mathrm{~g} / \mathrm{cm}^{3}$. En total se analizaron 3 muestras, identificando 300 minerales translúcidos. Finalmente los minerales se agruparon de acuerdo con el grado de estabilidad en ultraestables, estables e inestables (Mange y Maurer, 1992).

\section{Geocronología detrítica U-Pb en circón}

Fueron analizados circones de una muestra por la técnica $\mathrm{U}-\mathrm{Pb}$ de ablación laser acoplada a un espectrómetro de masa (LA-ICP-MS). La preparación fue realizada en los laboratorios Zirchron LLC (EE. UU.) y los análisis fueron realizados en Washington State University, Pullman, Estados Unidos, siguiendo los procedimientos analíticos indicados por Chang et al. (2006).

Los análisis fueron realizados sobre los núcleos con el fin de evitar circones con historias complejas (Gehrels et al., 2006). Para edades mayores a $850 \mathrm{Ma}$, se reporta la edad ${ }^{207} \mathrm{~Pb} /{ }^{206} \mathrm{~Pb}$, mientras que para edades menores a $850 \mathrm{Ma}$, se reporta la edad ${ }^{206} \mathrm{~Pb} /{ }^{238} \mathrm{U}$; la discordancia normal e inversa fue calculada para edades mayores a $500 \mathrm{Ma}$, eliminando aquellas que superaran el 15\% de discordancia; además se aplicó un filtro de error analítico para todas las edades, descartando todos los datos con más del $10 \%$ de error. Las edades fueron calculadas utilizando el programa Isoplot 3.62 (Ludwig, 2007).

\section{Resultados}

Las muestras fueron tomadas en el flanco occidental de la Cordillera Oriental, en la vía que conduce de Honda a Guaduas. En total se colectaron 5 muestras de areniscas de la Formación Cimarrona, para las cuales se realizaron conteos de granos en secciones delgadas en todas las muestras, conteo de minerales pesados en montaje de granos en 3 de ellas y geocronología $\mathrm{U}-\mathrm{Pb}$ en circones detríticos en una muestra; además en dos afloramientos correspondientes al segmento $\mathrm{Ca}$ y $\mathrm{Cc}$ respectivamente fue realizado un conteo de clastos de conglomerados para cada uno. Las muestras pueden agruparse en dos petrofacies, que coinciden con los segmentos $\mathrm{Ca}$ (muestras C-01, $\mathrm{C}-06$ y C-07) y $\mathrm{Cc}$ (C-03 y C-04). Los resultados de la petrografía convencional, la discriminación detallada de fragmentos líticos y los minerales pesados normalizados a porcentaje se encuentra en la Tabla 1, Tabla 2 y Tabla 3 respectivamente. 


\begin{tabular}{|c|c|c|c|c|c|c|c|c|c|c|c|c|c|c|c|c|c|c|c|c|c|c|c|c|c|}
\hline \multirow{3}{*}{ Segmento } & \multirow{3}{*}{ Muestra } & \multicolumn{20}{|c|}{ Armazón } & \multirow{2}{*}{\multicolumn{3}{|c|}{ Intersticial }} & \multirow{3}{*}{$\begin{array}{l}\text { Puntos } \\
\text { Totales }\end{array}$} \\
\hline & & \multicolumn{6}{|c|}{ Cuarzo } & \multicolumn{2}{|c|}{ Feldespato } & \multicolumn{3}{|c|}{ Líticos } & \multicolumn{9}{|c|}{ Accesorios } & & & & \\
\hline & & Qm & Qs & Qpf & Qpp & Qpd & Qc & $\mathrm{Pl}$ & $\mathrm{Fk}$ & Ls & $\mathrm{Lm}$ & Lv & Cal & Ms & $\mathrm{Zr}$ & Chl & Еp & Tur & Glc & $\mathrm{Ox}-\mathrm{Fe}$ & Fos & Mat. & Cem. & Por. & \\
\hline \multirow{2}{*}{$\begin{array}{c}\text { Segmento } \\
\text { Cc }\end{array}$} & C-03 & 34,3 & 0,0 & 0,6 & 1,1 & 10,9 & 4,0 & 2,9 & 0,0 & 3,4 & 3,1 & 9,7 & 0,3 & 0,0 & 0,0 & 0,0 & 0,0 & 0,0 & 1,1 & 0,0 & 1,4 & 27,1 & 0,0 & 0,0 & 350 \\
\hline & C- 04 & 55,5 & 0,0 & 0,7 & 1,8 & 11,0 & 6,0 & 0,0 & 0,0 & 0,7 & 7,8 & 1,1 & 0,4 & 1,1 & 0,4 & 0,4 & 0,4 & 0,0 & 0,0 & 1,8 & 0,0 & 11,0 & 3,0 & 0,0 & 281 \\
\hline \multirow{3}{*}{$\begin{array}{c}\text { Segmento } \\
\text { Ca }\end{array}$} & C-01 & 32,2 & 0,3 & 0,8 & 1,4 & 21,6 & 7,1 & 0,0 & 1,1 & 2,2 & 3,0 & 0,5 & 0,3 & 0,0 & 0,0 & 0,0 & 0,0 & 0,0 & 0,0 & 1,1 & 0,3 & 27,6 & 0,0 & 0,5 & 366 \\
\hline & C-07 & 58,7 & 0,0 & 0,7 & 0,4 & 9,4 & 8,0 & 0,0 & 0,0 & 1,8 & 1,8 & 1,1 & 0,0 & 0,0 & 0,0 & 0,0 & 0,0 & 0,0 & 0,0 & 4,3 & 0,0 & 8,3 & 5,4 & 0,0 & 276 \\
\hline & C-06 & 34,8 & 0,4 & 1,1 & 1,9 & 20,0 & 26,7 & 0,0 & 0,0 & 5,2 & 1,9 & 3,0 & 0,4 & 0,0 & 0,0 & 0,0 & 0,0 & 0,4 & 0,0 & 3,7 & 0,0 & 0,0 & 0,0 & 0,7 & 270 \\
\hline
\end{tabular}

Tabla 2. Resultados del conteo de puntos en la petrografía de alta resolución de areniscas discriminando entre los diferentes tipos de cuarzo y líticos, normalizados a porcentaje (\%) (Qp2-3: cuarzo policristalino compuesto por 2 o 3 cristales; Qp>3: cuarzo policristalino compuesto por más de 3 cristales; Qrec: cuarzo monocristalino con extinción recta; Qond: cuarzo monocristalino con extinción ondulatoria; Lsl: lítico sedimentario de lodolita; Lsa: lítico sedimentario de arenisca; Lc: lítico calcáreo; Lmf: lítico metamórfico filítico; Lmem: lítico metamórfico de esquisto moscovítico; Lmc: Lítico de metacaliza; Lmqs: lítico metamórfico cuarzo-sericítico; Lvf: lítico volcánico felsítico; Lvm: lítico volcánico microlítico; Lvl: lítico volcánico lathwork).

\begin{tabular}{|c|c|c|c|c|c|c|c|c|c|c|c|c|c|c|c|c|c|}
\hline \multirow{2}{*}{ Segmento } & \multirow{2}{*}{ Muestra } & \multicolumn{4}{|c|}{ Tipos de cuarzo } & \multirow{2}{*}{$\begin{array}{l}\text { Puntos } \\
\text { totales }\end{array}$} & \multicolumn{10}{|c|}{ Tipos de líticos } & \multirow{2}{*}{$\begin{array}{l}\text { Puntos } \\
\text { totales }\end{array}$} \\
\hline & & Qp2-3 & $\mathrm{Qp}>3$ & Qrec & Qond & & Lsl & Lsa & $\mathrm{Lc}$ & Lmf & Lmem & Lmc & Lmqs & Lvf & Lvm & Lvl & \\
\hline \multirow{2}{*}{$\begin{array}{c}\text { Segmento } \\
\text { Cc }\end{array}$} & C-03 & 2,4 & 24,4 & 20,7 & 52,4 & 164 & 12,3 & 0,0 & 8,8 & 5,3 & 5,3 & 3,5 & 5,3 & 5,3 & 5,3 & 49,1 & 57 \\
\hline & C-04 & 3,1 & 16,5 & 24,7 & 55,7 & 194 & 3,7 & 3,7 & 0,0 & 22,2 & 40,7 & 0,0 & 18,5 & 3,7 & 3,7 & 3,7 & 27 \\
\hline \multirow{3}{*}{$\begin{array}{c}\text { Segmento } \\
\text { Ca }\end{array}$} & C-01 & 5,9 & 36,6 & 24,9 & 32,7 & 205 & 33,3 & 0,0 & 4,8 & 0,0 & 0,0 & 9,5 & 42,9 & 4,8 & 0,0 & 4,8 & 21 \\
\hline & C-07 & 1,1 & 14,1 & 15,7 & 69,1 & 191 & 15,4 & 23,1 & 0,0 & 0,0 & 7,7 & 0,0 & 30,8 & 15,4 & 0,0 & 7,7 & 13 \\
\hline & C-06 & 2,7 & 33,8 & 27,0 & 36,5 & 148 & 51,9 & 0,0 & 0,0 & 7,4 & 0,0 & 0,0 & 11,1 & 11,1 & 0,0 & 18,5 & 27 \\
\hline
\end{tabular}

Tabla 3. Resultados del conteo de puntos de minerales pesados, normalizados a porcentaje (\%) (Zrn: circón; Rt: rutilo; Tur: turmalina; Ap: apatito; Grt: granate; Ep: epidota; Czo: clinozoicita; Zo: zoicita; Ms: moscovita; Bt: biotita; Chl: clorita; Glc: glauconita; Hbl: hornblenda; Cpx: clinopiroxeno).

\begin{tabular}{|c|c|c|c|c|c|c|c|c|c|c|c|c|c|c|c|c|c|}
\hline \multirow{2}{*}{ Segmento } & \multirow{2}{*}{ Muestra } & \multicolumn{3}{|c|}{ Ultraestable } & \multicolumn{6}{|c|}{ Estable } & \multicolumn{5}{|c|}{ Inestable } & \multirow{2}{*}{$\begin{array}{l}\text { Puntos } \\
\text { totales }\end{array}$} & \multirow{2}{*}{ Opacos } \\
\hline & & Zrn & Rt & Tur & Ap & Grt & Ep & Czo & Zo & Ms & Bt & Chl & Glc & Hbl & Cpx & & \\
\hline $\begin{array}{c}\text { Segmento } \\
\text { Cc }\end{array}$ & C-03 & 27,2 & 0,6 & 3,2 & 5,8 & 4,2 & 2,9 & 5,8 & 1,3 & 7,4 & 6,4 & 4,5 & 30,8 & 0,0 & 0,0 & 312 & 726 \\
\hline Segmento & C-01 & 42,0 & 3,2 & 2,6 & 4,4 & 0,9 & 0,0 & 0,0 & 2,0 & 43,5 & 1,5 & 0,0 & 0,0 & 0,0 & 0,0 & 345 & 328 \\
\hline $\mathrm{Ca}$ & C- 06 & 37,5 & 1,1 & 10,8 & 0,0 & 0,0 & 0,0 & 2,5 & 2,8 & 42,2 & 1,1 & 0,0 & 0,0 & 1,1 & 0,8 & 360 & 471 \\
\hline
\end{tabular}




\section{Conteo de clastos de conglomerados}

Los conglomerados pertenecientes al segmento $\mathrm{Ca}$ comprenden fragmentos de $1 \mathrm{~cm}$ hasta $7 \mathrm{~cm}$ de diámetro, varían de clasto soportados a matriz soportados, con cemento silíceo. Los granos son redondeados a muy redondeados y de baja esfericidad, la matriz es de tamaño arena gruesa y representa un $20 \%$ del total de la roca en los lugares donde son matriz soportados. La matriz es de igual composición que el armazón, sin embargo, los fragmentos son subangulares predominantemente. Por otro lado, aunque los conglomerados del segmento Cc comparten características texturales con el segmento $\mathrm{Ca}$, presentando clastos redondeados a subredondeados y de baja esfericidad, con un tamaño comprendido entre $1 \mathrm{~cm}$ y $8 \mathrm{~cm}$ de diámetro y matriz tamaño arena gruesa que oscila entre $20 \%$ y $25 \%$, se observan ligeras diferencias composicionales, como la presencia de cemento calcáreo $(\sim 5 \%)$, y fragmentos de bioclastos relativamente abundantes que no se encontraron en el segmento anterior.

La composición de los clastos identificados en el conteo de conglomerados en ambos segmentos no presenta una variación considerable. El componente predominante es cuarzo lechoso de aspecto policristalino, el cual se asemeja al cuarzo observado en venas, con proporciones entre $66,7 \%$ y $68,1 \%$, este es seguido en proporción por clastos de chert, que fueron diferenciados según su coloración teniendo porcentajes variables de chert negro $(1,7 \%-5,3 \%)$, chert gris $(2,6 \%)$, chert blanco $(2,6 \%$ $3,5 \%)$ y chert pardo-amarillento $(0,9 \%)$. Además, se encontraron componentes menos representativos en ambos segmentos como cuarzo rosado (7\%), líticos de arenisca (3,5\%-5,2\%), líticos de neis (2,6\%-5,3\%), cuarzo cristal de roca $(0,9 \%-4,3 \%)$, cuarzo ahumado (0,9\%-2,6\%), líticos de esquisto $(0,9 \%-1,8 \%)$ y líticos plutónicos $(0,9 \%-1,8 \%)$. Finalmente, en el segmento Cc se identificaron clastos de jaspe $(0,9 \%)$ y bioclastos $(0,9 \%)$ que no están presentes en el segmento $\mathrm{Ca}$ (Figura 2).

\section{Petrografía y minerales pesados}

\section{Segmento Ca:}

Las tres muestras del segmento $\mathrm{Ca}$ incluyen areniscas conglomeráticas tanto en la parte inferior como superior con clastos entre $2 \mathrm{~mm}$ y $3 \mathrm{~cm}$ de diámetro. Las partículas del armazón presentan dos modas en la redondez, una angular y otra redondeada, con una predominancia de los granos redondeados, así como una baja esfericidad. En general las rocas son inmaduras texturalmente (Figura 4), con una alta madurez composicional, como lo sugiere los contenidos de cuarzo mayores al 90\% (Figura 4).

El porcentaje de matriz se incrementa progresivamente de $0,0 \%$ a $27,6 \%$, pasando de tener matriz limo-arcillosa con cemento ferruginoso a matriz calcárea con cemento calcáreo. Los contactos entre los granos son suturados en la parte inferior del segmento y cambian a flotantes en la parte superior por el mayor contenido de matriz.

Las rocas corresponden a sublitoarenitas (Folk, 1980) compuestas principalmente por cuarzo que oscila entre 90,2\%-94,3\% con una proporción de fragmentos líticos menor entre 5,8\%-10,6\% y una cantidad de feldespatos muy baja comprendida entre $0,0 \%$ y $1,6 \%$ (Figura $5 \mathrm{~A})$. Los fragmentos de cuarzo son principalmente monocristalinos $(57,6 \%-84,8 \%)$ y en menor medida policristalinos $(15,2 \%-42,4 \%)$. Este segmento se caracteriza por una proporción de cuarzo monocristalino con extinción ondulatoria mayor que el cuarzo monocristalino con extinción recta (Figura 5B).

Los tipos de cuarzo policristalino identificados en las muestras de este segmento incluyen principalmente cuarzo policristalino difuso $(40,3 \%-69,3 \%)$ y cuarzo chert $(22,8 \%-53,3 \%)$ con menores cantidades de cuarzo policristalino poligonal $(2,0 \%-4,4 \%)$, foliado $(2,2 \%-3,9 \%)$ y cuarzo sedimentario $(0,7 \%-0,9 \%)$. Los minerales accesorios en las muestras incluyen turmalina, calcedonia, óxidos de hierro y bioclastos calcáreos.

En la petrografía de las areniscas se discriminó entre los diferentes tipos de cuarzo (cuarzo monocristalino con extinción ondulatoria (Qond), cuarzo monocristalino con extinción recta (Qrec), cuarzo policristalino compuesto por 2 o 3 cristales (Qp 2-3) y cuarzo policristalino compuesto por más de 3 cristales $(\mathrm{Qp}>3)$ ) propuestos en Basu et al. (1975), identificando en el segmento Ca un mayor porcentaje de cuarzo monocristalino y cuarzo policristalino de más de tres cristales con respecto a los demás tipos. De este modo, usando el diagrama de discriminación de posibles áreas fuente para los sedimentos propuesto por Basu et al. (1975), las muestras tendrían un aporte de rocas de bajo grado metamórfico (Figura 5C).

Todas las rocas de este segmento caen en el campo de orógeno reciclado, en el diagrama de discriminación de ambiente tectónico Qm-F-Lt propuesto por Dickinson (1985), mientras que en el diagrama de discriminación tectónica propuesto por Garzanti (2016) están en el campo de bloque continental (Figura 5D). 


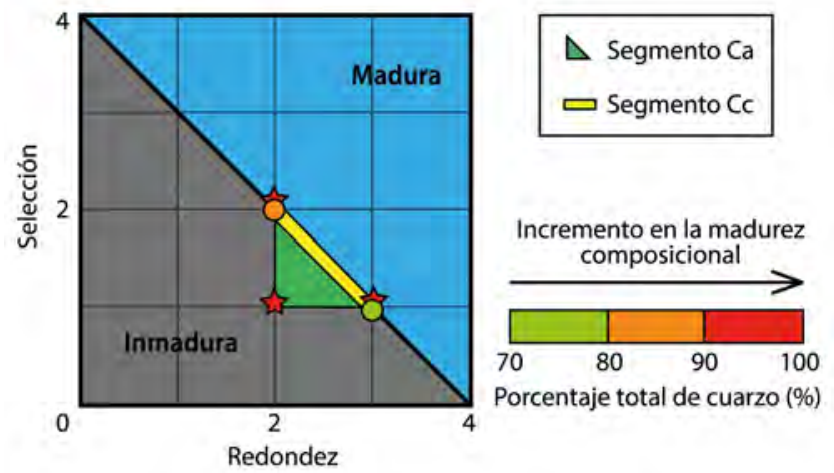

Figura 4. Evaluación de la madurez composicional y textural a partir de la descripción de campo de los conglomerados, siguiendo a Zimmermann y Hall (2016). El triángulo verde representa el campo de variación de la madurez textural del segmento Ca (delimitado por estrellas) y el recuadro amarillo representa el campo de variación de madurez textural del segmento Cc (delimitado por círculos). Los colores de las muestras de cada segmento corresponden al contenido porcentual de cuarzo reflejando su grado de madurez respectivo (extremo inferior derecho de la figura). Las categorías texturales de 1 a 4 son asignadas de acuerdo con la redondez y selección de los granos. Las categorías de la selección son (1) pobremente seleccionado, (2) moderadamente seleccionado, (3) bien seleccionado y (4) muy bien seleccionado. Las categorías de la redondez son (1) angular, (2) sub-angular, (3) sub-redondeado y (4) redondeado.
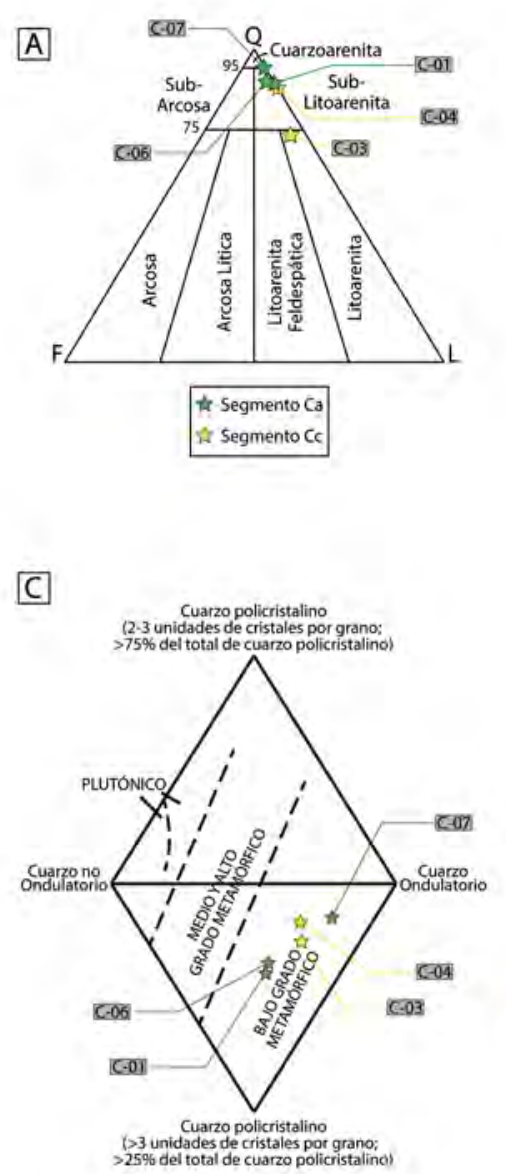

B
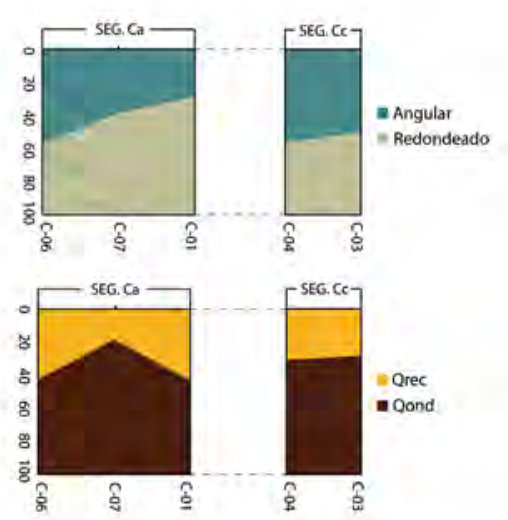

D]

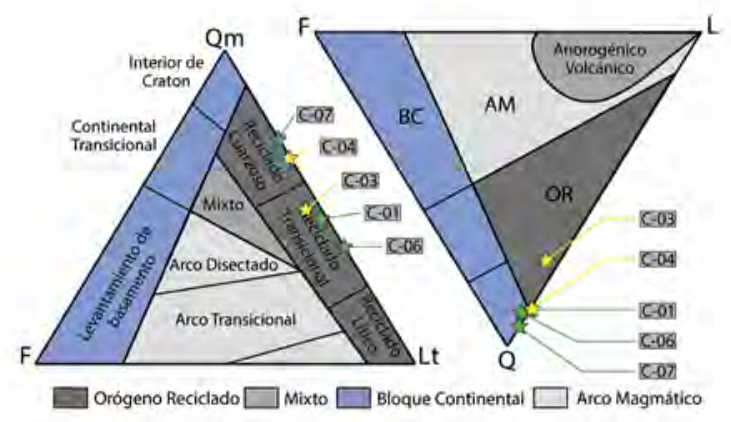

Figura 5. A. Diagrama de clasificación Q-F-L según Folk (1980). B. Diagrama de distribución porcentual de cuarzo con extinción recta (Qrec) vs cuarzo con extinción ondulatoria (Qond) y diagrama de distribución porcentual de la redondez del cuarzo para cada segmento. C. Diagrama de discriminación de posibles áreas fuente para los sedimentos según Basu et al. (1975). D. Diagramas de discriminación tectónica de arenisca. Diagrama Qm-F-Lt según Dickinson (1985) y diagrama Q-F-L según Garzanti (2016). 
Los fragmentos de roca presentes en las areniscas del segmento Ca corresponden principalmente a líticos sedimentarios $(72,3 \%-86,9 \%)$ presentando una menor cantidad porcentual de líticos metamórficos $(5,0 \%$ $23,4 \%$ ) y líticos volcánicos (4,2\%-8,6\%) (Figura 6A). Los líticos sedimentarios están representados fundamentalmente por fragmentos de chert y lodolitas, los cuales son más abundantes en la parte inferior del segmento. Los líticos volcánicos corresponden a líticos de textura lathwork y felsítica, los cuales están presentes de forma casi constante a lo largo del segmento. Finalmente los fragmentos de roca metamórficos provienen de rocas con metamorfismo de muy bajo a bajo grado, y están representados en mayor medida por líticos metamórficos cuarzo-sericíticos y líticos filíticos, con menor aporte de líticos de metacalizas y líticos de esquistos moscovíticos (Figura 6B).

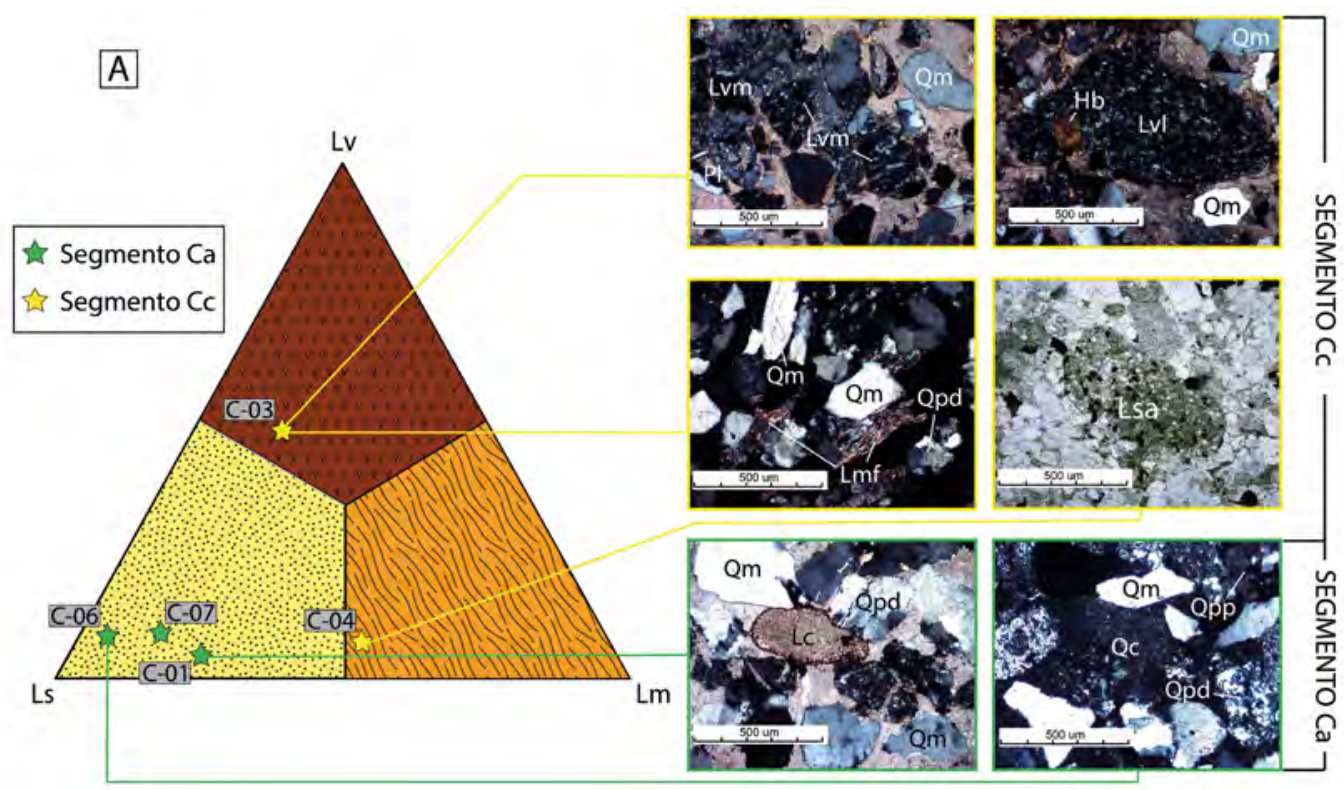

B
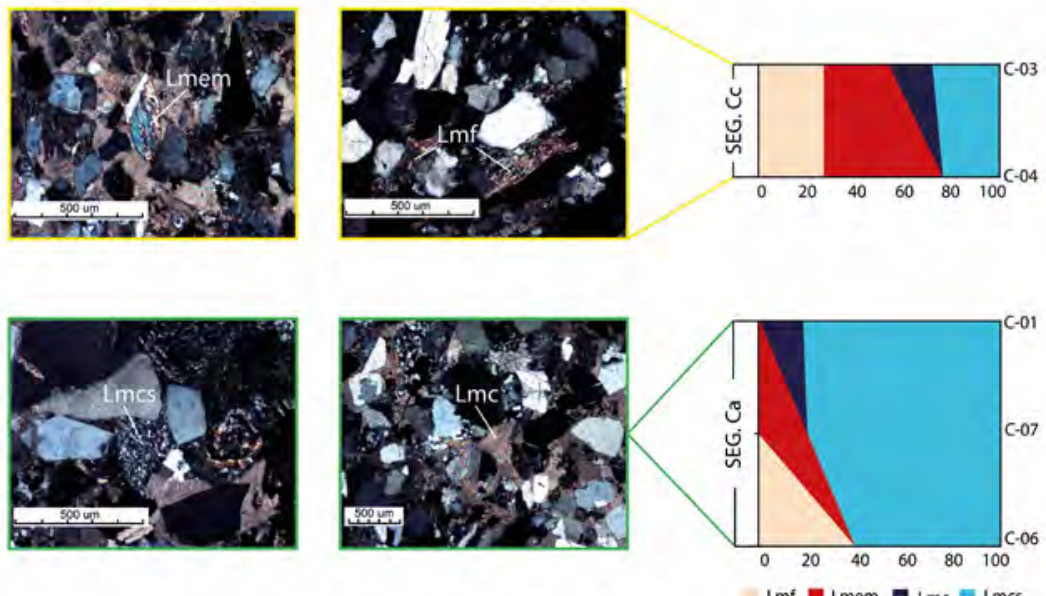

Figura 6. A. Diagrama de distribución de líticos sedimentarios, volcánicos y metamórficos (Ls-Lv-Lm) mostrando las características composicionales de cada segmento (microfotografías de las muestras en la parte derecha de la figura). B. Diagrama de distribución porcentual de líticos metamórficos según Garzanti y Vezzoli (2003). Abreviatura Lmf: Lítico metamórfico filítico, Lmem: Lítico metamórfico de esquisto moscovítico, Lmc: Lítico metamórfico de metacaliza, Lcms: Lítico metamórfico cuarzosericítico, Qm: cuarzo monocristalino, Qpd: cuarzo policristalino difuso, Qpp: cuarzo policristalino poligonal, Qc: chert, Lsa: lítico de arenisca, Lc: lítico calcáreo, Lvl: lítico volcánico lathwork, Lvm: lítico volcánico microlítico, Hb: hornblenda. 
Las areniscas presentan minerales pesados inestables, estables y ultraestables. Los ultraestables están representados fundamentalmente por circón con porcentajes que oscilan entre $37,5 \%$ y $42,0 \%$, la turmalina y el rutilo son las otras fases minerales ultraestables con porcentajes entre $2,6 \%$ y $10,8 \%$ y entre $1,1 \%$ y $3,2 \%$ respectivamente (Figura $7 \mathrm{~A}$ ). Los minerales estables presentan una distribución semejante a los ultraestables (Figura 7B), con la moscovita (42,2\%-43,5\%) como mineral dominante, acompañada de clinozoicita y zoicita en la muestra inferior, y apatito, granate y zoicita en la muestra más superior. Finalmente, los minerales inestables no superan el 4\% (Figura 7B), y están representados por biotita, hornblenda y augita en la parte inferior, $\mathrm{y}$ biotita en la parte superior.

Al agrupar los minerales pesados, es posible reconocer una afinidad con áreas fuente que está en el límite entre metamórfica-reciclada $(50,2 \%-52,2 \%)$ y ácidaintermedia $(47,8 \%-48,8 \%)$, con aporte muy bajo de fuentes básicas-ultrabásicas $(1,0 \%)$ en la parte inferior (Figura 7B).

\section{A}
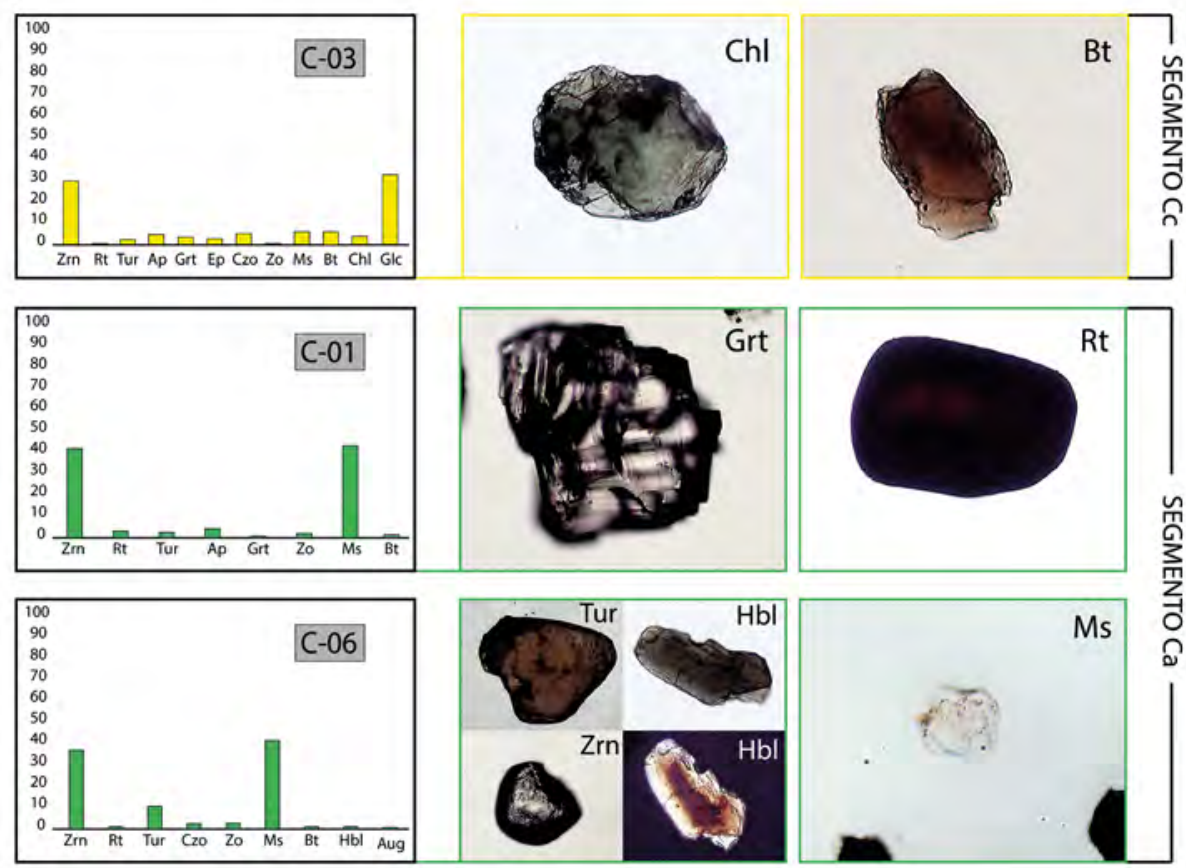

B

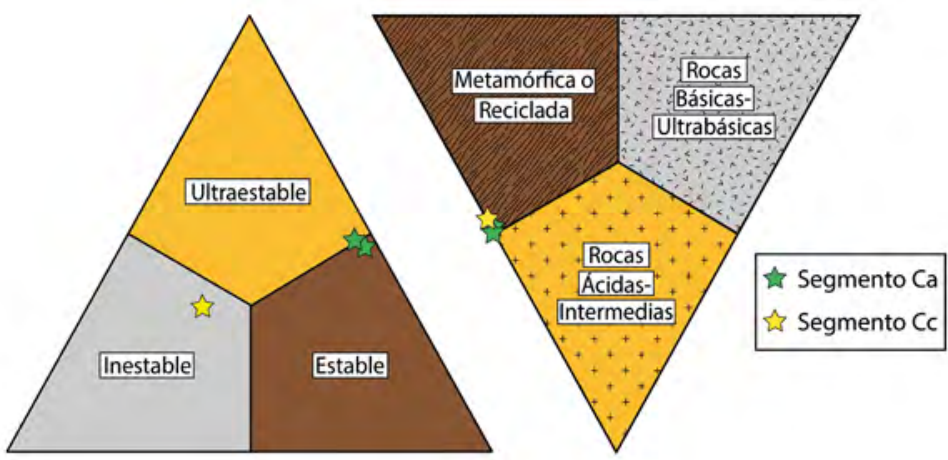

Figura 7. A. Resultados del análisis de minerales pesados. Abreviaturas: Ap: apatito, Bt: biotita, Chl: clorita, Czo: clinozoicita, Ep: epidota, Glc: glauconita, Grt: granate, Hbl: hornblenda, Ms: moscovita, Rt: rutilo, Tur: turmalina, Zr: circón, Zs: zoisita. B. Diagrama de estabilidad de minerales pesados y diagrama de posibles áreas fuente según Mange y Maurer (1992). 


\section{Segmento Cc:}

Las areniscas de este segmento son de carácter conglomerático, con un tamaño de grano arena gruesa. La redondez está caracterizada por dos modas al igual que en el segmento anterior, aunque hay un incremento en la proporción de cuarzo angular con respecto al cuarzo redondeado, además, se caracterizan por tener baja esfericidad. Las areniscas del segmento Cc muestran menor madurez textural y clastos subangulares a sub-redondeados, además de contenidos de cuarzo menores a $90 \%$, indicando una menor madurez composicional que el segmento anterior (Figura 4).

La muestra inferior presenta matriz limosa $(11,0 \%)$ con cemento silíceo $(3,0 \%)$, mientras que la superior presenta matriz calcárea $(27,1 \%)$, e incluye contactos flotantes entre los granos. Las rocas varían de sublitoarenita a litoarenita (Folk, 1980) y presentan contenidos menores de cuarzo con respecto al segmento anterior, los cuales varían entre $72,7 \%$ y $88,7 \%$. Además se observa un incremento gradual en el porcentaje de líticos, oscilando entre $11,3 \%$ y $23,3 \%$, y un pequeño incremento en el contenido del feldespato de hasta un $4 \%$ en la parte superior (Figura 5A). De igual forma predominan los fragmentos de cuarzo monocristalinos $(73,2 \%-80,4 \%)$ sobre los fragmentos de cuarzo policristalinos (19,6\%-26,8\%). Este segmento se caracteriza por una proporción de cuarzo monocristalino con extinción ondulatoria mayor que el cuarzo monocristalino con extinción recta (Figura 5B).

Los tipos de cuarzo policristalino encontrados en este segmento están representados predominantemente por cuarzo policristalino difuso $(56,4 \%-65,5 \%)$ y cuarzo chert (24,1\%-30,9\%), con menores cantidades de cuarzo policristalino poligonal $(6,9 \%-9,1 \%)$ y foliado (3,4\%-3,6\%). Además, este segmento se caracteriza por la ausencia de cuarzo sedimentario. Los minerales accesorios de este segmento comprenden clorita, epidota, circón, moscovita, calcedonia, óxidos de hierro, glauconita y fósiles.

$\mathrm{Al}$ igual que las rocas del segmento $\mathrm{Ca}$, las muestras se caracterizan por presentar un mayor porcentaje de cuarzo monocristalino ondulatorio y cuarzo policristalino de más de tres cristales. De este modo, la fuente principal correspondería a rocas de bajo grado metamórfico (Figura 5C). En los diagramas de discriminación tectónica (Dickinson, 1985; Garzanti, 2016), las muestras de este segmento caen en el campo de orógeno reciclado (Figura 5D).
Las partículas de roca en este segmento están representadas por líticos metamórficos, que disminuyen de base a techo (15,5\%-50\%), y líticos volcánicos, estos últimos con mayor proporción hacia el tope del intervalo (6,8\%-47,9\%) (Figura 6A). Adicionalmente, estas muestras presentan un aporte más limitado de líticos sedimentarios en comparación con el segmento anterior, con una proporción que varía entre $36,6 \%$ y $43,2 \%$ (Figura 6A). Los líticos metamórficos, a pesar de ser de muy bajo a bajo grado metamórfico, muestran una mayor proporción de esquistos moscovíticos con respecto al segmento Ca. También se encontraron líticos filíticos, líticos de metacalizas y metapsamitas (Figura 6B). Los líticos sedimentarios incluyen fragmentos de chert y lodolitas, con líticos de areniscas en menor proporción. Los líticos volcánicos son principalmente de textura lathwork, con presencia de líticos felsíticos y microlíticos (Dickinson, 1970; Figura 6A). Los minerales accesorios en este segmento están representados por moscovita, glauconita, bioclastos calcedonia, circón, clorita y epidota.

El circón es la fase ultraestable predominante en este segmento, alcanzando un $27,2 \%$ del total de la muestra, las fases ultraestables que aparecen en menor medida en la roca son la turmalina $(3,2 \%)$ y el rutilo $(0,6 \%)$ (Figura 7A). El incremento en la proporción de los minerales inestables (Figura 7B) está acompañado además por un aumento en la diversidad de las fases, las cuales están representadas por moscovita $(7,4 \%)$, clinozoicita $(5,8 \%)$, apatito $(5,8 \%)$, granate $(4,2 \%)$, epidota $(2,9 \%)$ y zoicita $(1,3 \%)$. La fase mineral inestable predominante es la glauconita que alcanza un $30,8 \%$ en la muestra, con un aporte minoritario de biotita $(6,4 \%)$ y clorita $(4,5 \%)$ (Figura $7 \mathrm{~A})$.

Los minerales pesados indican una posible área fuente que está en el límite entre metamórfica-reciclada $(53,5 \%)$ y ácida-intermedia $(46,5 \%)$, con ningún aporte de fuentes básicas-ultrabásicas (Figura 7B).

\section{Geocronología detrítica U-Pb en circón}

Fueron analizados 100 circones de la muestra (C01) perteneciente al segmento Ca (Figura 8A). En la Tabla 4 se encuentran los resultados obtenidos en la geocronología $\mathrm{U}-\mathrm{Pb}$ realizada en circones detríticos de la muestra C-01.

Los cristales son predominantemente prismáticos y euhedrales con una relación largo:ancho (L:W) de 3:1 y $2: 1$, con granos subredondeados y redondeados en 
menor proporción. Las relaciones $\mathrm{Th} / \mathrm{U}$ varían de 0,09 a 1,9 , sugiriendo la predominancia de circones ígneos (Rubatto, 2002), excepto por tres granos con relaciones $\mathrm{Th} / \mathrm{U}$ comprendidas entre 0,01 y 0,05 con edades de $257,4 \pm 3,6 \mathrm{Ma}, 464,6 \pm 6,8$ Ma y 491,6 \pm 8 Ma, lo que podría indicar un posible origen metamórfico (Rubatto, 2002). Los picos de edad principales son del Cretácico Superior (72 Ma, 75,6 Ma y 82,8 Ma) (Figura 8B y 8C), Jurásico (153-161 Ma) y de edad Permo-Triásica (276-246 Ma) con picos menos representativos de edad Paleozoica a Proterozoica ( 400-1,100 Ma) (Figura 8B).

La apropiada definición de la edad máxima de acumulación establecida con la geocronología detrítica ha sido objeto de discusión (Dickinson y Gehrels, 2009; Spencer et al., 2016; Herriott et al., 2019; Copeland, 2020). Existen diferentes propuestas, incluyendo la edad del pico de distribución de edades más joven en el histograma o la media ponderada de tres o más granos (Dickinson y Gehrels, 2009), cuyo valor descansa en el supuesto de que la repetición de la edad en diferentes granos no podría estar relacionada a posibles trayectorias de pérdidas de $\mathrm{Pb}$. Sin embargo, recientemente algunos autores consideran que esta aproximación puede ser inapropiada, ya que los granos no necesariamente están relacionados a la misma fuente, así que, salvo que se tenga otro amarre composicional en el circón, es más apropiado analizar la edad máxima de acumulación a partir del grano de circón más joven (Spencer et al., 2016; Herriott et al., 2019; Copeland, 2020).

En la Formación Cimarrona, la edad del circón más joven restringe su máxima edad de depositación al Maastrichtiano $(66,1 \pm 1,9 \mathrm{Ma})$. Las edades más jóvenes obtenidas con el pico de distribución de edades (72,0 Ma) y con la media de granos de circón que se sobreponen en el error (70,3 $\pm 1,5 \mathrm{Ma})$, respaldan la edad de acumulación Maastrichtiana.

Fueron comparadas las poblaciones de circones detríticos publicadas de diferentes unidades geológicas que pueden ser área fuente o contemporáneas con la acumulación de la Formación Cimarrona, incluyendo áreas fuentes de la Cordillera Central como lo son rocas metamórficas pre-Cretácicas del Complejo Cajamarca, rocas volcano-sedimentarias Cretácicas del Complejo Quebradagrande y las formaciones San Luis y Abejorral, así como con la Formación Umir que estaría subyaciendo la Formación Cimarrona; además se incluye una recopilación de edades de rocas del Cretácico Inferior de la Cordillera Oriental para evaluar su posible influencia como área de aporte de sedimentos de la Formación Cimarrona (Figura 8D).
La evaluación de las poblaciones de circones detríticos para estas unidades indica para los metasedimentos Jurásicos y Pre-Triásicos del Complejo Cajamarca picos de distribución del Jurásico (165 Ma), PérmicoTriásico (249-286 Ma) y el Neoproterozoico (553$640 \mathrm{Ma}$ ) con algunos menos representativos de edad Mesoproterozoica (1000-1218 Ma). El Complejo Quebradagrande presenta picos representativos del Cretácico Inferior (107 Ma), Pérmico-Triásico (237$260 \mathrm{Ma})$ y Cámbricos-Neoproterozoicos (495-630 Ma) con algunas edades menos características Jurásicas (147-191 Ma) y Proterozoicas (1056 Ma). Las rocas que representan el Cretácico Inferior de la Cordillera Oriental (Chipaque, Une, Guadalupe, Macanal, Buenavista y Las Juntas) incluyen un pico de edad característico Mesoproterozoico (1023 Ma) con algunas edades menos importantes Cretácicas (154 Ma) y Pérmicas (267 Ma). La Formación San Luis del Cretácico Inferior presenta picos principales de edad Jurásica (149 Ma), PérmicoTriásica (222-276 Ma) y Carbonífera (341 Ma), con picos menores Cretácicos (119-136 Ma), CámbricosNeoproterozoicos (423-636 Ma) y Mesoproterozoicos (1030 Ma). La Formación Abejorral presenta un pico representativo Pérmico-Triásico (244-270 Ma) con picos menos representativos de edad Cretácica InferiorJurásica (101-149 Ma), Cámbrica-Neoproterozoica (462-610 Ma) y Mesoproterozoica (1035 Ma).

Al comparar el conjunto de poblaciones que caracterizan las diferentes unidades de la Cordillera Central y aquellas poblaciones diferentes a las del Cretácico Superior de la Formación Cimarrona es posible observar semejanzas significativas con la distribución de edades de los sedimentos cretácicos de la Formación San Luis y la Formación Abejorral (Figura 8D), los cuales serían inicialmente representativos de las coberteras sedimentarias de la Cordillera Central.

Las rocas de la Formación Umir presentan picos Cretácicos y Jurásicos (102 Ma; 152-168 Ma) como los más representativos, además de edades Pérmicas (274 Ma) menos características, mostrando, de igual forma, semejanzas a la suprayacente Formación Cimarrona (Figura 8D).

Por otro lado, las rocas del Cretácico Inferior de la Cordillera Oriental presentan un pico de edad Mesoproterozoíco (1023 Ma) que no está presente en la Formación Cimarrona ni en la Formación Umir, lo que apoya la idea de que la procedencia es efectivamente del occidente, a partir de una ancestral Cordillera Central (Figura 8D). 
A

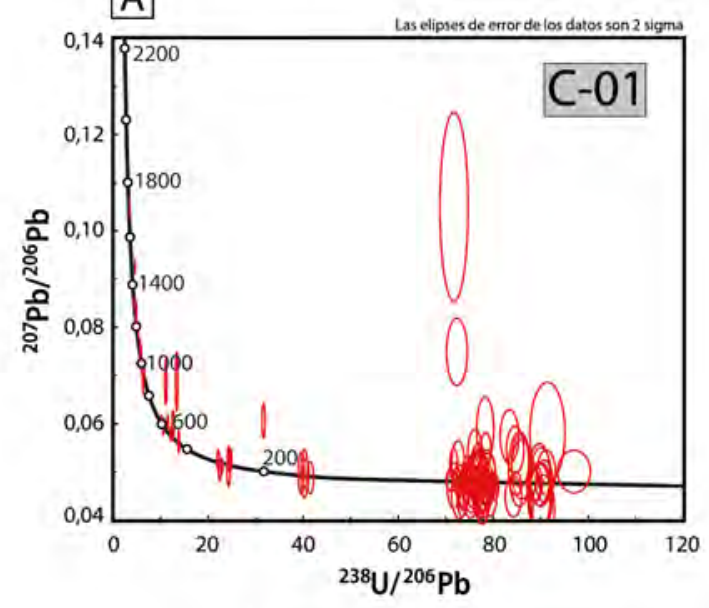

B

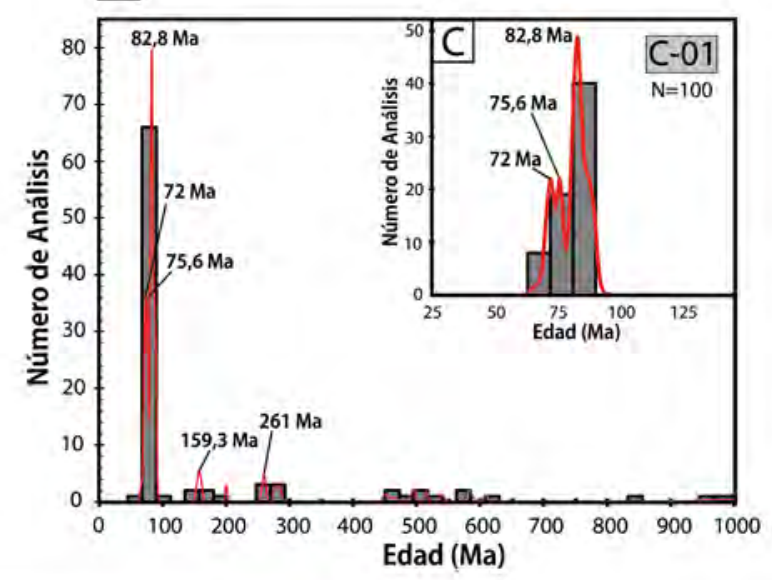

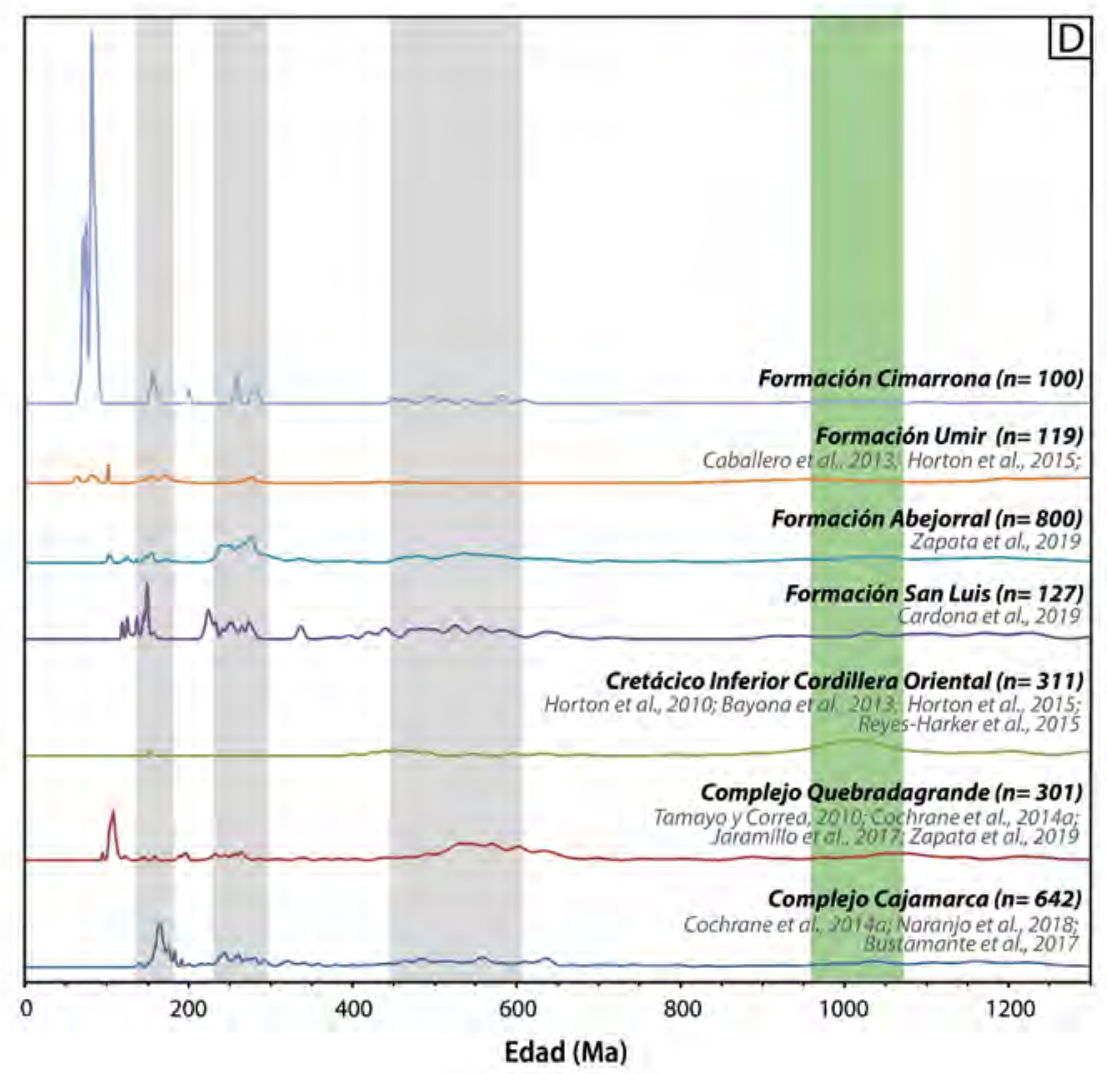

Figura 8. A. Diagrama de concordia Tera-Wasserburg para la muestra de arenisca analizada. B. Gráfico de densidad de probabilidad mostrando los resultados de la geocronología U-Pb en circones detríticos para la muestra de la Formación Cimarrona analizada (los picos de edades principales están señalados en la figura). C. Acercamiento a los picos cretácicos mostrados en B. D. Gráficos de densidad de probabilidad comparativos que muestran distribuciones de edades U-Pb de circones detríticos publicadas (Jaramillo et al., 2017; Naranjo et al., 2018; Cochrane et al., 2014a; Bustamante et al., 2017; Horton et al., 2010, 2015; Bayona et al., 2013; Reyes-Harker et al., 2015; Zapata et al., 2019; Tamayo y Correa, 2010; Caballero et al., 2013; Cardona et al., 2020) de diferentes unidades geológicas ubicadas en la Cordillera Central, Cordillera Oriental y Valle del Magdalena. Las barras verticales de color gris representan edades diagnósticas de la Formación San Luis como área de aporte, la barra vertical verde representa el rango de edades de las Unidades del Cretácico Inferior de la Cordillera Oriental que las descarta como fuentes de sedimentos. 
Tabla 4. Resultados de la geocronología U-Pb en circones detríticos.

\begin{tabular}{|c|c|c|c|c|c|c|c|c|c|c|c|c|c|c|c|c|c|c|c|}
\hline \multirow[b]{2}{*}{ Muestra } & \multirow[b]{2}{*}{ U ppm } & \multirow[b]{2}{*}{$\begin{array}{l}\text { U/ } \\
\text { Th }\end{array}$} & \multicolumn{9}{|c|}{ Radios Isotópicos } & \multicolumn{6}{|c|}{ Edades } & \multirow[b]{2}{*}{$\begin{array}{c}\text { Mejor } \\
\text { Edad } \\
\text { Ma }\end{array}$} & \multirow[b]{2}{*}{$\begin{array}{c}\sigma \\
\text { Error } \\
\text { Abs } \\
\text { Ma }\end{array}$} \\
\hline & & & $\begin{array}{l}{ }^{207} \mathbf{P b} / \\
{ }^{235} \mathbf{U}\end{array}$ & $\begin{array}{c}2 \sigma \\
\text { Error } \\
\text { Abs }\end{array}$ & $\begin{array}{c}{ }^{206} \mathrm{~Pb} / \\
{ }^{238} \mathbf{U}\end{array}$ & $\begin{array}{c}2 \sigma \\
\text { Error } \\
\text { Abs }\end{array}$ & $\begin{array}{l}\text { Coef. } \\
\text { Corr. }\end{array}$ & 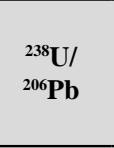 & $\begin{array}{c}2 \sigma \\
\text { Error } \\
\text { Abs }\end{array}$ & $\begin{array}{l}{ }^{207} \mathrm{~Pb} / \\
{ }^{206} \mathrm{~Pb}\end{array}$ & $\begin{array}{c}2 \sigma \\
\text { Error } \\
\text { Abs }\end{array}$ & $\begin{array}{c}{ }^{207} \mathbf{P b} / \\
{ }^{235} \mathbf{U} \\
\mathbf{M a}\end{array}$ & $\begin{array}{c}\sigma \\
\text { Error } \\
\text { Abs } \\
\text { Ma } \\
\end{array}$ & $\begin{array}{c}{ }^{206} \mathrm{~Pb} / \\
{ }^{238} \mathrm{U} \\
\mathrm{Ma}\end{array}$ & $\begin{array}{c}\sigma \\
\text { Error } \\
\text { Abs } \\
\text { Ma } \\
\end{array}$ & $\begin{array}{c}{ }^{207} \mathrm{~Pb} / \\
{ }^{206} \mathrm{~Pb} \\
\mathrm{Ma}\end{array}$ & $\begin{array}{c}\sigma \\
\text { Error } \\
\text { Abs } \\
\text { Ma } \\
\end{array}$ & & \\
\hline C-01-1 & 447,0 & 2,2 & 0,0799 & 0,0061 & 0,0129 & 0,0002 & 0,1870 & 77,7605 & 1,3907 & 0,0449 & 0,0036 & 78,1 & 6,1 & 82,7 & 1,5 & n.c. & n.c. & 82,7 & 1,5 \\
\hline C-01-2 & 166,0 & 1,6 & 0,0820 & 0,0110 & 0,0136 & 0,0003 & 0,0162 & 73,7463 & 1,5772 & 0,0452 & 0,0061 & 81,0 & 10,0 & 86,8 & 1,9 & n.c. & n.c. & 86,8 & 1,9 \\
\hline C-01-3 & 183,4 & 1,9 & 0,0798 & 0,0071 & 0,0130 & 0,0002 & 0,0013 & 77,1010 & 1,2484 & 0,0454 & 0,0041 & 77,1 & 6,6 & 83,1 & 1,3 & n.c. & n.c. & 83,1 & 1,3 \\
\hline C-01-4 & 226,9 & 1,3 & 0,0784 & 0,0062 & 0,0126 & 0,0002 & 0,0017 & 79,3651 & 1,1338 & 0,0454 & 0,0037 & 76,0 & 5,8 & 80,7 & 1,2 & n.c. & n.c. & 80,7 & 1,2 \\
\hline C-01-5 & 149,0 & 1,8 & 0,0794 & 0,0086 & 0,0129 & 0,0002 & 0,0061 & 77,7001 & 1,3282 & 0,0453 & 0,0050 & 76,4 & 8,1 & 82,4 & 1,4 & n.c. & n.c. & 82,4 & 1,4 \\
\hline C-01-6 & 92,6 & 2,0 & 0,0720 & 0,0110 & 0,0118 & 0,0003 & 0,0004 & 84,8896 & 2,0178 & 0,0439 & 0,0066 & 69,0 & 10,0 & 75,5 & 1,8 & n.c. & n.c. & 75,5 & 1,8 \\
\hline C-01-7 & 72,7 & 1,6 & 0,0710 & 0,0150 & 0,0118 & 0,0003 & 0,0486 & 84,6740 & 2,1509 & 0,0438 & 0,0094 & 66,0 & 14,0 & 75,7 & 1,9 & n.c. & n.c. & 75,7 & 1,9 \\
\hline C-01-8 & 58,1 & 3,0 & 1,5180 & 0,0520 & 0,1594 & 0,0016 & 0,0929 & 6,2735 & 0,0630 & 0,0692 & 0,0024 & 932,0 & 21,0 & 953,4 & 8,7 & 850,0 & 73,0 & 953,4 & 8,7 \\
\hline C-01-9 & 286,0 & 2,4 & 0,0730 & 0,0055 & 0,0119 & 0,0002 & 0,2187 & 84,2460 & 1,4195 & 0,0450 & 0,0035 & 71,0 & 5,2 & 76,1 & 1,3 & n.c. & n.c. & 76,1 & 1,3 \\
\hline C-01-10 & 233,0 & 2,1 & 0,0841 & 0,0069 & 0,0136 & 0,0002 & 0,0002 & 73,4754 & 0,9178 & 0,0455 & 0,0039 & 81,2 & 6,5 & 87,2 & 1,1 & n.c. & n.c. & 87,2 & 1,1 \\
\hline C-01-11 & 204,4 & 2,1 & 0,0822 & 0,0067 & 0,0129 & 0,0002 & 0,0912 & 77,7605 & 1,0884 & 0,0465 & 0,0038 & 79,4 & 6,3 & 82,4 & 1,2 & n.c. & n.c. & 82,4 & 1,2 \\
\hline C-01-12 & 343,0 & 1,4 & 0,3102 & 0,0084 & 0,0438 & 0,0003 & 0,1116 & 22,8258 & 0,1771 & 0,0512 & 0,0014 & 273,5 & 6,5 & 276,4 & 2,1 & 231,0 & 59,0 & 276,4 & 2,1 \\
\hline C-01-13 & 999,0 & 5,3 & 1,7360 & 0,0260 & 0,1725 & 0,0015 & 0,3242 & 5,7971 & 0,0504 & 0,0726 & 0,0011 & 1021,2 & 9,8 & 1025,8 & 8,5 & 997,0 & 31,0 & 1025,8 & 8,5 \\
\hline C-01-14 & 215,2 & 2,4 & 0,0692 & 0,0056 & 0,0113 & 0,0002 & 0,0003 & 88,3392 & 1,4827 & 0,0442 & 0,0037 & 67,4 & 5,3 & 72,6 & 1,2 & n.c. & n.c. & 72,6 & 1,2 \\
\hline C-01-15 & 243,4 & 1,5 & 0,0801 & 0,0056 & 0,0129 & 0,0002 & 0,1054 & 77,5194 & 0,9615 & 0,0451 & 0,0031 & 77,7 & 5,2 & 82,6 & 1,0 & n.c. & n.c. & 82,6 & 1,0 \\
\hline C-01-16 & 168,5 & 1,3 & 0,0709 & 0,0066 & 0,0127 & 0,0002 & 0,0663 & 78,8644 & 1,3683 & 0,0407 & 0,0038 & 69,6 & 6,4 & 81,2 & 1,4 & n.c. & n.c. & 81,2 & 1,4 \\
\hline C-01-17 & 128,3 & 0,8 & 4,2420 & 0,0590 & 0,2948 & 0,0017 & 0,1120 & 3,3921 & 0,0196 & 0,1046 & 0,0014 & 1680,0 & 12,0 & 1665,4 & 8,6 & 1701,0 & 26,0 & 1701,0 & 26,0 \\
\hline C-01-18 & 215,4 & 2,4 & 0,0749 & 0,0057 & 0,0110 & 0,0002 & 0,1884 & 91,1577 & 1,5788 & 0,0499 & 0,0038 & 72,9 & 5,4 & 70,3 & 1,2 & 100,0 & 150,0 & 70,3 & 1,2 \\
\hline C-01-19 & 208,0 & 1,4 & 0,0894 & 0,0060 & 0,0129 & 0,0002 & 0,0399 & 77,3395 & 1,3159 & 0,0502 & 0,0034 & 86,3 & 5,6 & 82,8 & 1,4 & 130,0 & 140,0 & 82,8 & 1,4 \\
\hline C-01-20 & 210,0 & 1,4 & 0,0874 & 0,0061 & 0,0127 & 0,0002 & 0,0215 & 78,8644 & 1,2439 & 0,0498 & 0,0034 & 84,4 & 5,7 & 81,2 & 1,2 & 100,0 & 130,0 & 81,2 & 1,2 \\
\hline C-01-21 & 158,9 & 1,9 & 0,0962 & 0,0082 & 0,0131 & 0,0002 & 0,0958 & 76,1615 & 1,2761 & 0,0533 & 0,0046 & 92,2 & 7,6 & 84,1 & 1,4 & 170,0 & 170,0 & 84,1 & 1,4 \\
\hline C-01-22 & 133,7 & 2,0 & 0,0659 & 0,0084 & 0,0111 & 0,0002 & 0,0000 & 89,8473 & 1,9374 & 0,0449 & 0,0057 & 64,7 & 8,2 & 71,3 & 1,5 & n.c. & n.c. & 71,3 & 1,5 \\
\hline C-01-23 & 189,6 & 1,4 & 0,2210 & 0,0390 & 0,0139 & 0,0005 & 0,7892 & 71,7360 & 2,4186 & 0,1050 & 0,0160 & 191,0 & 31,0 & 89,2 & 3,0 & 1120,0 & 290,0 & 89,2 & 3,0 \\
\hline C-01-24 & 265,0 & 2,0 & 0,1032 & 0,0094 & 0,0128 & 0,0002 & 0,1401 & 78,3085 & 1,4717 & 0,0589 & 0,0054 & 98,7 & 8,6 & 81,8 & 1,6 & 400,0 & 180,0 & 81,8 & 1,6 \\
\hline C-01-25 & 174,2 & 1,1 & 0,7770 & 0,0170 & 0,0950 & 0,0007 & 0,0113 & 10,5319 & 0,0799 & 0,0593 & 0,0014 & 582,0 & 9,7 & 584,7 & 4,3 & 551,0 & 51,0 & 584,7 & 4,3 \\
\hline C-01-26 & 357,5 & 2,4 & 0,7790 & 0,0140 & 0,0942 & 0,0007 & 0,3458 & 10,6191 & 0,0801 & 0,0601 & 0,0010 & 584,0 & 7,7 & 580,1 & 4,2 & 595,0 & 35,0 & 580,1 & 4,2 \\
\hline C-01-27 & 82,9 & 5,7 & 3,4370 & 0,0880 & 0,1793 & 0,0019 & 0,3336 & 5,5772 & 0,0591 & 0,1393 & 0,0034 & 1509,0 & 20,0 & 1063,0 & 10,0 & 2206,0 & 43,0 & 2206,0 & 43,0 \\
\hline C-01-28 & 612,0 & 2,5 & 0,0926 & 0,0033 & 0,0141 & 0,0002 & 0,2407 & 71,1744 & 0,9118 & 0,0483 & 0,0018 & 90,1 & 3,2 & 90,0 & 1,1 & 89,0 & 74,0 & 90,0 & 1,1 \\
\hline
\end{tabular}




\begin{tabular}{|c|c|c|c|c|c|c|c|c|c|c|c|c|c|c|c|c|c|c|c|}
\hline \multirow[b]{2}{*}{ Muestra } & \multirow[b]{2}{*}{ U ppm } & \multirow[b]{2}{*}{$\begin{array}{l}\text { U/ } \\
\text { Th }\end{array}$} & \multicolumn{9}{|c|}{ Radios Isotópicos } & \multicolumn{6}{|c|}{ Edades } & \multirow[b]{2}{*}{$\begin{array}{c}\text { Mejor } \\
\text { Edad } \\
\text { Ma }\end{array}$} & \multirow[b]{2}{*}{$\begin{array}{c}\sigma \\
\text { Error } \\
\text { Abs } \\
\text { Ma }\end{array}$} \\
\hline & & & $\begin{array}{c}{ }^{207} \mathbf{P b} / \\
{ }^{235} \mathbf{U}\end{array}$ & $\begin{array}{c}2 \sigma \\
\text { Error } \\
\text { Abs }\end{array}$ & $\begin{array}{c}{ }^{206} \mathbf{P b} / \\
{ }^{238} \mathbf{U}\end{array}$ & $\begin{array}{c}2 \sigma \\
\text { Error } \\
\text { Abs }\end{array}$ & $\begin{array}{l}\text { Coef. } \\
\text { Corr. }\end{array}$ & $\begin{array}{l}{ }^{238} \mathrm{U} / \\
{ }^{206} \mathrm{~Pb}\end{array}$ & $\begin{array}{c}2 \sigma \\
\text { Error } \\
\text { Abs }\end{array}$ & $\begin{array}{l}{ }^{207} \mathrm{~Pb} / \\
{ }^{206} \mathrm{~Pb}\end{array}$ & $\begin{array}{c}2 \sigma \\
\text { Error } \\
\text { Abs }\end{array}$ & $\begin{array}{c}{ }^{207} \mathbf{P b} / \\
{ }^{235} \mathbf{U} \\
\mathrm{Ma}\end{array}$ & $\begin{array}{c}\sigma \\
\text { Error } \\
\text { Abs } \\
\text { Ma }\end{array}$ & $\begin{array}{c}{ }^{206} \mathrm{~Pb} / \\
{ }^{238} \mathrm{U} \\
\mathrm{Ma}\end{array}$ & $\begin{array}{c}\sigma \\
\text { Error } \\
\text { Abs } \\
\text { Ma }\end{array}$ & $\begin{array}{c}{ }^{207} \mathrm{~Pb} / \\
{ }^{206} \mathrm{~Pb} \\
\mathrm{Ma}\end{array}$ & $\begin{array}{c}\sigma \\
\text { Error } \\
\text { Abs } \\
\text { Ma }\end{array}$ & & \\
\hline C-01-29 & 152,5 & 1,8 & 1,7360 & 0,0290 & 0,1689 & 0,0011 & 0,0644 & 5,9207 & 0,0386 & 0,0746 & 0,0013 & 1020,0 & 11,0 & 1005,7 & 6,2 & 1048,0 & 35,0 & 1005,7 & 6,2 \\
\hline C-01-30 & 166,9 & 2,5 & 0,1683 & 0,0087 & 0,0246 & 0,0003 & 0,0000 & 40,6009 & 0,4780 & 0,0497 & 0,0026 & 156,9 & 7,6 & 156,8 & 1,8 & 120,0 & 110,0 & 156,8 & 1,8 \\
\hline C-01-31 & 379,0 & 2,9 & 0,0979 & 0,0052 & 0,0140 & 0,0001 & 0,1747 & 71,6846 & 0,6680 & 0,0515 & 0,0028 & 95,0 & 4,9 & 89,3 & 0,8 & 180,0 & 110,0 & 89,3 & 0,8 \\
\hline C-01-32 & 222,0 & 3,0 & 0,0835 & 0,0069 & 0,0117 & 0,0002 & 0,0447 & 85,6898 & 1,4685 & 0,0523 & 0,0044 & 80,7 & 6,4 & 74,8 & 1,3 & 140,0 & 150,0 & 74,8 & 1,3 \\
\hline C-01-33 & 160,0 & 2,0 & 0,0863 & 0,0080 & 0,0132 & 0,0002 & 0,0005 & 75,8150 & 1,2645 & 0,0478 & 0,0044 & 83,0 & 7,5 & 84,5 & 1,4 & n.c. & n.c. & 84,5 & 1,4 \\
\hline C-01-34 & 391,8 & 3,2 & 0,0851 & 0,0039 & 0,0132 & 0,0001 & 0,1292 & 75,9301 & 0,7495 & 0,0468 & 0,0022 & 82,7 & 3,7 & 84,4 & 0,8 & n.c. & n.c. & 84,4 & 0,8 \\
\hline C-01-35 & 268,1 & 2,3 & 0,0738 & 0,0046 & 0,0113 & 0,0002 & 0,0124 & 88,8889 & 1,1852 & 0,0476 & 0,0030 & 72,5 & 4,5 & 72,1 & 0,9 & n.c. & n.c. & 72,1 & 0,9 \\
\hline C-01-36 & 1053,0 & 1,1 & 0,0888 & 0,0029 & 0,0130 & 0,0001 & 0,0005 & 77,2201 & 0,5963 & 0,0496 & 0,0017 & 86,3 & 2,7 & 82,9 & 0,7 & n.c. & n.c. & 82,9 & 0,7 \\
\hline C-01-37 & 116,6 & 2,1 & 0,0648 & 0,0092 & 0,0110 & 0,0002 & 0,0817 & 90,5797 & 1,8871 & 0,0422 & 0,0059 & 62,3 & 8,7 & 70,8 & 1,5 & n.c. & n.c. & 70,8 & 1,5 \\
\hline C-01-38 & 280,0 & 3,9 & 1,5020 & 0,0310 & 0,1527 & 0,0018 & 0,2055 & 6,5488 & 0,0772 & 0,0712 & 0,0015 & 930,0 & 13,0 & 915,8 & 9,9 & 950,0 & 44,0 & 915,8 & 9,9 \\
\hline C-01-39 & 207,8 & 2,1 & 0,1470 & 0,0130 & 0,0138 & 0,0003 & 0,4222 & 72,3589 & 1,7802 & 0,0749 & 0,0057 & 138,0 & 12,0 & 88,5 & 2,2 & 990,0 & 160,0 & 88,5 & 2,2 \\
\hline C-01-40 & 485,5 & 1,6 & 0,0966 & 0,0055 & 0,0128 & 0,0002 & 0,3034 & 78,4314 & 0,9227 & 0,0546 & 0,0029 & 93,1 & 5,0 & 81,7 & 1,0 & 290,0 & 110,0 & 81,7 & 1,0 \\
\hline C-01-41 & 304,1 & 2,4 & 0,0730 & 0,0041 & 0,0113 & 0,0002 & 0,0001 & 88,4956 & 1,1747 & 0,0472 & 0,0028 & 71,2 & 3,9 & 72,5 & 0,9 & 10,0 & 120,0 & 72,5 & 0,9 \\
\hline C-01-42 & 140,7 & 1,3 & 0,2830 & 0,0130 & 0,0412 & 0,0005 & 0,0007 & 24,3013 & 0,2657 & 0,0500 & 0,0024 & 251,0 & 10,0 & 259,9 & 2,8 & 156,0 & 98,0 & 259,9 & 2,8 \\
\hline C-01-43 & 211,1 & 1,7 & 0,0862 & 0,0061 & 0,0136 & 0,0002 & 0,0281 & 73,6920 & 1,0318 & 0,0461 & 0,0033 & 83,4 & 5,7 & 86,9 & 1,2 & n.c. & n.c. & 86,9 & 1,2 \\
\hline C-01-44 & 490,0 & 2,4 & 2,7680 & 0,0330 & 0,2170 & 0,0019 & 0,2824 & 4,6083 & 0,0403 & 0,0926 & 0,0011 & 1346,3 & 8,8 & 1265,6 & 9,9 & 1480,0 & 23,0 & 1480,0 & 23,0 \\
\hline C-01-45 & 347,4 & 2,5 & 0,0885 & 0,0058 & 0,0130 & 0,0002 & 0,0234 & 76,8049 & 1,0028 & 0,0495 & 0,0033 & 85,7 & 5,4 & 83,4 & 1,1 & 110,0 & 130,0 & 83,4 & 1,1 \\
\hline C-01-46 & 42,7 & 19,1 & 0,8560 & 0,0490 & 0,0903 & 0,0015 & 0,0350 & 11,0742 & 0,1840 & 0,0687 & 0,0039 & 621,0 & 26,0 & 556,8 & 8,6 & 790,0 & 120,0 & 556,8 & 8,6 \\
\hline C-01-47 & 120,7 & 1,9 & 2,3580 & 0,0570 & 0,2055 & 0,0020 & 0,2882 & 4,8662 & 0,0474 & 0,0830 & 0,0019 & 1227,0 & 17,0 & 1205,0 & 11,0 & 1259,0 & 45,0 & 1205,0 & 11,0 \\
\hline C-01-48 & 276,0 & 2,8 & 0,0694 & 0,0058 & 0,0114 & 0,0002 & 0,0372 & 88,1057 & 1,5525 & 0,0445 & 0,0038 & 67,6 & 5,5 & 72,7 & 1,2 & n.c. & n.c. & 72,7 & 1,2 \\
\hline C-01-49 & 191,0 & 1,9 & 0,3100 & 0,0120 & 0,0446 & 0,0005 & 0,1542 & 22,4165 & 0,2261 & 0,0505 & 0,0019 & 272,6 & 9,4 & 281,3 & 2,8 & 190,0 & 83,0 & 281,3 & 2,8 \\
\hline C-01-50 & 174,1 & 2,2 & 0,0896 & 0,0066 & 0,0118 & 0,0002 & 0,2366 & 84,6024 & 1,5031 & 0,0546 & 0,0040 & 86,4 & 6,2 & 75,8 & 1,4 & 260,0 & 150,0 & 75,8 & 1,4 \\
\hline C-01-51 & 100,1 & 1,8 & 0,1680 & 0,0130 & 0,0248 & 0,0004 & 0,0001 & 40,2577 & 0,5997 & 0,0496 & 0,0041 & 155,0 & 11,0 & 158,5 & 2,3 & 60,0 & 150,0 & 158,5 & 2,3 \\
\hline C-01-52 & 119,8 & 1,5 & 0,1720 & 0,0120 & 0,0253 & 0,0004 & 0,1118 & 39,5726 & 0,5481 & 0,0498 & 0,0035 & 159,0 & 10,0 & 160,9 & 2,2 & 90,0 & 130,0 & 160,9 & 2,2 \\
\hline C-01-53 & 513,0 & 1,9 & 2,6960 & 0,0240 & 0,2297 & 0,0012 & 0,3029 & 4,3535 & 0,0227 & 0,0852 & 0,0007 & 1327,3 & 6,7 & 1332,7 & 6,4 & 1317,0 & 17,0 & 1317,0 & 17,0 \\
\hline C-01-54 & 163,0 & 1,7 & 0,0853 & 0,0088 & 0,0133 & 0,0003 & 0,0011 & 75,2445 & 1,4154 & 0,0465 & 0,0049 & 83,0 & 8,4 & 85,1 & 1,6 & n.c. & n.c. & 85,1 & 1,6 \\
\hline C-01-55 & 392,0 & 1,2 & 0,0908 & 0,0046 & 0,0137 & 0,0002 & 0,0413 & 72,8863 & 1,0625 & 0,0483 & 0,0026 & 87,9 & 4,3 & 87,9 & 1,3 & n.c. & n.c. & 87,9 & 1,3 \\
\hline C-01-56 & 502,0 & 1,5 & 0,0815 & 0,0041 & 0,0125 & 0,0001 & 0,1488 & 80,1282 & 0,8347 & 0,0470 & 0,0023 & 79,3 & 3,8 & 80,0 & 0,8 & n.c. & n.c. & 80,0 & 0,8 \\
\hline C-01-57 & 116,4 & 1,8 & 0,0814 & 0,0099 & 0,0126 & 0,0003 & 0,0172 & 79,5545 & 1,8354 & 0,0469 & 0,0058 & 77,9 & 9,2 & 80,5 & 1,9 & n.c. & n.c. & 80,5 & 1,9 \\
\hline
\end{tabular}




\begin{tabular}{|c|c|c|c|c|c|c|c|c|c|c|c|c|c|c|c|c|c|c|c|}
\hline \multirow[b]{2}{*}{ Muestra } & \multirow[b]{2}{*}{ U ppm } & \multirow[b]{2}{*}{$\begin{array}{l}\text { U/ } \\
\text { Th }\end{array}$} & \multicolumn{9}{|c|}{ Radios Isotópicos } & \multicolumn{6}{|c|}{ Edades } & \multirow[b]{2}{*}{$\begin{array}{c}\text { Mejor } \\
\text { Edad } \\
\text { Ma }\end{array}$} & \multirow[b]{2}{*}{$\begin{array}{c}\sigma \\
\text { Error } \\
\text { Abs } \\
\text { Ma }\end{array}$} \\
\hline & & & $\begin{array}{l}{ }^{207} \mathbf{P b} / \\
{ }^{235} \mathbf{U}\end{array}$ & $\begin{array}{c}2 \sigma \\
\text { Error } \\
\text { Abs }\end{array}$ & $\begin{array}{l}{ }^{206} \mathrm{~Pb} / \\
{ }^{238} \mathbf{U}\end{array}$ & $\begin{array}{c}2 \sigma \\
\text { Error } \\
\text { Abs }\end{array}$ & $\begin{array}{l}\text { Coef. } \\
\text { Corr. }\end{array}$ & $\begin{array}{l}{ }^{238} \mathbf{U} / \\
{ }^{206} \mathbf{P b}\end{array}$ & $\begin{array}{c}2 \sigma \\
\text { Error } \\
\text { Abs }\end{array}$ & $\begin{array}{l}{ }^{207} \mathrm{~Pb} / \\
{ }^{206} \mathrm{~Pb}\end{array}$ & $\begin{array}{c}2 \sigma \\
\text { Error } \\
\text { Abs }\end{array}$ & $\begin{array}{c}{ }^{207} \mathbf{P b} / \\
{ }^{235} \mathbf{U} \\
\mathbf{M a}\end{array}$ & $\begin{array}{c}\sigma \\
\text { Error } \\
\text { Abs } \\
\text { Ma } \\
\end{array}$ & $\begin{array}{c}{ }^{206} \mathrm{~Pb} / \\
{ }^{238} \mathrm{U} \\
\mathrm{Ma}\end{array}$ & $\begin{array}{c}\sigma \\
\text { Error } \\
\text { Abs } \\
\text { Ma } \\
\end{array}$ & $\begin{array}{c}{ }^{207} \mathrm{~Pb} / \\
{ }^{206} \mathrm{~Pb} \\
\mathrm{Ma}\end{array}$ & $\begin{array}{c}\sigma \\
\text { Error } \\
\text { Abs } \\
\text { Ma } \\
\end{array}$ & & \\
\hline C-01-58 & 299,0 & 0,7 & 0,5610 & 0,0190 & 0,0724 & 0,0007 & 0,1280 & 13,8122 & 0,1278 & 0,0563 & 0,0019 & 450,0 & 12,0 & 450,6 & 4,0 & 448,0 & 72,0 & 450,6 & 4,0 \\
\hline C-01-59 & 222,2 & 1,8 & 0,0909 & 0,0070 & 0,0130 & 0,0002 & 0,0032 & 76,8640 & 1,2998 & 0,0510 & 0,0040 & 88,3 & 6,6 & 83,3 & 1,4 & n.c. & n.c. & 83,3 & 1,4 \\
\hline C-01-60 & 406,0 & 1,7 & 0,6360 & 0,0110 & 0,0799 & 0,0005 & 0,0776 & 12,5188 & 0,0737 & 0,0577 & 0,0010 & 499,5 & 6,7 & 495,4 & 2,8 & 505,0 & 39,0 & 495,4 & 2,8 \\
\hline C-01-61 & 244,0 & 2,2 & 0,0961 & 0,0082 & 0,0120 & 0,0002 & 0,4297 & 83,4028 & 1,5999 & 0,0574 & 0,0045 & 92,1 & 7,5 & 76,8 & 1,5 & n.c. & n.c. & 76,8 & 1,5 \\
\hline C-01-62 & 132,3 & 2,0 & 0,0863 & 0,0085 & 0,0130 & 0,0002 & 0,0047 & 76,8640 & 1,4179 & 0,0488 & 0,0049 & 83,8 & 8,1 & 83,3 & 1,5 & n.c. & n.c. & 83,3 & 1,5 \\
\hline C-01-63 & 192,8 & 1,6 & 0,0884 & 0,0069 & 0,0132 & 0,0002 & 0,0225 & 76,0456 & 1,2722 & 0,0492 & 0,0039 & 85,3 & 6,4 & 84,2 & 1,4 & n.c. & n.c. & 84,2 & 1,4 \\
\hline C-01-64 & 180,2 & 2,7 & 0,0977 & 0,0069 & 0,0138 & 0,0002 & 0,0005 & 72,6216 & 1,1075 & 0,0518 & 0,0038 & 93,8 & 6,3 & 88,1 & 1,3 & n.c. & n.c. & 88,1 & 1,3 \\
\hline C-01-65 & 460,0 & 34,3 & 0,2980 & 0,0120 & 0,0408 & 0,0006 & 0,2988 & 24,5399 & 0,3493 & 0,0525 & 0,0020 & 264,2 & 9,7 & 257,4 & 3,6 & 306,0 & 88,0 & 257,4 & 3,6 \\
\hline C-01-66 & 266,0 & 3,8 & 2,4130 & 0,0300 & 0,2153 & 0,0013 & 0,3766 & 4,6447 & 0,0280 & 0,0813 & 0,0009 & 1245,2 & 8,9 & 1257,0 & 6,8 & 1221,0 & 23,0 & 1257,0 & 6,8 \\
\hline C-01-67 & 156,3 & 2,6 & 0,0800 & 0,0081 & 0,0116 & 0,0002 & 0,1267 & 85,9845 & 1,7005 & 0,0506 & 0,0051 & 77,0 & 7,5 & 74,6 & 1,5 & n.c. & n.c. & 74,6 & 1,5 \\
\hline C-01-68 & 342,3 & 1,0 & 0,7260 & 0,0150 & 0,0872 & 0,0007 & 0,2387 & 11,4705 & 0,0855 & 0,0604 & 0,0012 & 553,1 & 8,9 & 538,8 & 3,9 & 602,0 & 44,0 & 538,8 & 3,9 \\
\hline C-01-69 & 42,7 & 20,1 & 0,6660 & 0,0440 & 0,0747 & 0,0011 & 0,0001 & 13,3869 & 0,1971 & 0,0688 & 0,0050 & 516,0 & 28,0 & 464,6 & 6,8 & 730,0 & 140,0 & 464,6 & 6,8 \\
\hline C-01-70 & 212,6 & 3,4 & 0,0888 & 0,0063 & 0,0131 & 0,0002 & 0,0378 & 76,3942 & 1,1672 & 0,0495 & 0,0036 & 86,4 & 6,0 & 83,8 & 1,3 & n.c. & n.c. & 83,8 & 1,3 \\
\hline C-01-71 & 160,6 & 1,4 & 0,1625 & 0,0089 & 0,0241 & 0,0003 & 0,0043 & 41,4938 & 0,5682 & 0,0488 & 0,0027 & 151,7 & 7,7 & 153,5 & 2,1 & 100,0 & 110,0 & 153,5 & 2,1 \\
\hline C-01-72 & 414,0 & 0,8 & 0,2640 & 0,0130 & 0,0316 & 0,0003 & 0,1448 & 31,6756 & 0,2709 & 0,0607 & 0,0030 & 236,0 & 10,0 & 200,3 & 1,7 & 521,0 & 95,0 & 200,3 & 1,7 \\
\hline C-01-73 & 218,6 & 2,6 & 0,0727 & 0,0052 & 0,0110 & 0,0002 & 0,0505 & 90,7441 & 1,4822 & 0,0481 & 0,0036 & 70,8 & 4,9 & 70,6 & 1,1 & n.c. & n.c. & 70,6 & 1,1 \\
\hline C-01-74 & 148,7 & 2,8 & 0,0887 & 0,0069 & 0,0139 & 0,0002 & 0,0007 & 71,7360 & 1,1836 & 0,0472 & 0,0039 & 86,3 & 6,6 & 89,2 & 1,5 & n.c. & n.c. & 89,2 & 1,5 \\
\hline C-01-75 & 164,4 & 1,8 & 0,0614 & 0,0062 & 0,0125 & 0,0002 & 0,1107 & 80,1925 & 1,3505 & 0,0353 & 0,0034 & 59,9 & 5,9 & 79,9 & 1,3 & n.c. & n.c. & 79,9 & 1,3 \\
\hline C-01-76 & 106,8 & 2,9 & 0,0820 & 0,0100 & 0,0117 & 0,0003 & 0,3520 & 85,5432 & 1,9026 & 0,0506 & 0,0063 & 79,7 & 9,7 & 74,9 & 1,6 & n.c. & n.c. & 74,9 & 1,6 \\
\hline C-01-77 & 389,0 & 1,8 & 0,8300 & 0,0150 & 0,0991 & 0,0008 & 0,3525 & 10,0888 & 0,0763 & 0,0606 & 0,0010 & 612,6 & 8,5 & 609,2 & 4,4 & 611,0 & 37,0 & 609,2 & 4,4 \\
\hline C-01-78 & 182,5 & 1,7 & 0,0812 & 0,0062 & 0,0128 & 0,0002 & 0,0510 & 78,3085 & 1,3491 & 0,0463 & 0,0036 & 78,7 & 5,8 & 81,8 & 1,4 & n.c. & n.c. & 81,8 & 1,4 \\
\hline C-01-79 & 475,0 & 3,4 & 1,8670 & 0,0200 & 0,1768 & 0,0009 & 0,3433 & 5,6551 & 0,0291 & 0,0764 & 0,0008 & 1068,5 & 7,0 & 1049,6 & 5,0 & 1100,0 & 20,0 & 1049,6 & 5,0 \\
\hline C-01-80 & 168,0 & 2,4 & 0,0771 & 0,0083 & 0,0119 & 0,0002 & 0,0007 & 84,0336 & 1,5536 & 0,0462 & 0,0051 & 74,3 & 7,8 & 76,2 & 1,4 & n.c. & n.c. & 76,2 & 1,4 \\
\hline C-01-81 & 227,1 & 2,5 & 1,6660 & 0,0310 & 0,1675 & 0,0013 & 0,0722 & 5,9701 & 0,0463 & 0,0721 & 0,0014 & 994,0 & 12,0 & 998,4 & 7,4 & 981,0 & 39,0 & 998,4 & 7,4 \\
\hline C-01-82 & 124,4 & 1,7 & 0,0850 & 0,0100 & 0,0136 & 0,0003 & 0,1308 & 73,7463 & 1,5228 & 0,0465 & 0,0058 & 81,8 & 9,8 & 86,8 & 1,8 & n.c. & n.c. & 86,8 & 1,8 \\
\hline C-01-83 & 449,0 & 1,6 & 0,6650 & 0,0120 & 0,0831 & 0,0005 & 0,1699 & 12,0294 & 0,0680 & 0,0579 & 0,0011 & 516,5 & 7,4 & 514,8 & 2,8 & 507,0 & 40,0 & 514,8 & 2,8 \\
\hline C-01-84 & 604,0 & 1,9 & 0,0782 & 0,0033 & 0,0118 & 0,0001 & 0,0147 & 84,7458 & 0,9336 & 0,0476 & 0,0020 & 76,3 & 3,1 & 75,6 & 0,8 & n.c. & n.c. & 75,6 & 0,8 \\
\hline C-01-85 & 100,5 & 2,9 & 0,0860 & 0,0120 & 0,0109 & 0,0004 & 0,0005 & 91,4077 & 3,0079 & 0,0582 & 0,0085 & 82,0 & 11,0 & 70,1 & 2,3 & 130,0 & 270,0 & 70,1 & 2,3 \\
\hline C-01-86 & 178,4 & 1,7 & 0,0912 & 0,0062 & 0,0134 & 0,0002 & 0,0384 & 74,7943 & 1,1748 & 0,0492 & 0,0034 & 88,0 & 5,8 & 85,6 & 1,3 & n.c. & n.c. & 85,6 & 1,3 \\
\hline
\end{tabular}




\begin{tabular}{|c|c|c|c|c|c|c|c|c|c|c|c|c|c|c|c|c|c|c|c|}
\hline \multirow[b]{2}{*}{ Muestra } & \multirow[b]{2}{*}{ U ppm } & \multirow[b]{2}{*}{$\begin{array}{l}\text { U/ } \\
\text { Th }\end{array}$} & \multicolumn{9}{|c|}{ Radios Isotópicos } & \multicolumn{6}{|c|}{ Edades } & \multirow[b]{2}{*}{$\begin{array}{c}\text { Mejor } \\
\text { Edad } \\
\text { Ma }\end{array}$} & \multirow[b]{2}{*}{$\begin{array}{c}\sigma \\
\text { Error } \\
\text { Abs } \\
\text { Ma }\end{array}$} \\
\hline & & & $\begin{array}{l}{ }^{207} \mathbf{P b} / \\
{ }^{235} \mathbf{U}\end{array}$ & $\begin{array}{c}2 \sigma \\
\text { Error } \\
\text { Abs }\end{array}$ & $\begin{array}{l}{ }^{206} \mathrm{~Pb} / \\
{ }^{238} \mathbf{U}\end{array}$ & $\begin{array}{c}2 \sigma \\
\text { Error } \\
\text { Abs }\end{array}$ & $\begin{array}{l}\text { Coef. } \\
\text { Corr. }\end{array}$ & $\begin{array}{l}{ }^{238} \mathrm{U} / \\
{ }^{206} \mathbf{P b}\end{array}$ & $\begin{array}{c}2 \sigma \\
\text { Error } \\
\text { Abs }\end{array}$ & $\begin{array}{l}{ }^{207} \mathbf{P b} / \\
{ }^{206} \mathbf{P b}\end{array}$ & $\begin{array}{c}2 \sigma \\
\text { Error } \\
\text { Abs }\end{array}$ & $\begin{array}{c}{ }^{207} \mathbf{P b} / \\
{ }^{235} \mathbf{U} \\
\mathbf{M a}\end{array}$ & $\begin{array}{c}\sigma \\
\text { Error } \\
\text { Abs } \\
\text { Ma }\end{array}$ & $\begin{array}{c}{ }^{206} \mathrm{~Pb} / \\
{ }^{238} \mathrm{U} \\
\mathrm{Ma}\end{array}$ & $\begin{array}{c}\sigma \\
\text { Error } \\
\text { Abs } \\
\text { Ma }\end{array}$ & $\begin{array}{c}{ }^{207} \mathrm{~Pb} / \\
{ }^{206} \mathrm{~Pb} \\
\mathrm{Ma}\end{array}$ & $\begin{array}{c}\sigma \\
\text { Error } \\
\text { Abs } \\
\text { Ma }\end{array}$ & & \\
\hline C-01-87 & 143,0 & 1,5 & 0,0812 & 0,0069 & 0,0128 & 0,0002 & 0,0002 & 77,9423 & 1,3973 & 0,0465 & 0,0041 & 79,3 & 6,6 & 82,2 & 1,5 & n.c. & n.c. & 82,2 & 1,5 \\
\hline C-01-88 & 170,8 & 2,0 & 0,0848 & 0,0072 & 0,0133 & 0,0002 & 0,1009 & 75,3580 & 1,2493 & 0,0465 & 0,0040 & 81,8 & 6,7 & 85,0 & 1,4 & n.c. & n.c. & 85,0 & 1,4 \\
\hline C-01-89 & 188,4 & 1,5 & 0,3280 & 0,0110 & 0,0452 & 0,0004 & 0,0438 & 22,1092 & 0,2102 & 0,0525 & 0,0018 & 286,5 & 8,4 & 285,2 & 2,7 & 273,0 & 74,0 & 285,2 & 2,7 \\
\hline C- $01-90$ & 172,0 & 2,6 & 0,0721 & 0,0067 & 0,0119 & 0,0002 & 0,0001 & 84,1043 & 1,5562 & 0,0446 & 0,0043 & 70,0 & 6,3 & 76,2 & 1,4 & n.c. & n.c. & 76,2 & 1,4 \\
\hline C-01-91 & 117,1 & 2,2 & 0,0750 & 0,0080 & 0,0112 & 0,0002 & 0,0002 & 89,6861 & 1,8500 & 0,0495 & 0,0052 & 72,4 & 7,5 & 71,5 & 1,4 & n.c. & n.c. & 71,5 & 1,4 \\
\hline C-01-92 & 147,2 & 1,7 & 0,0841 & 0,0072 & 0,0129 & 0,0002 & 0,0323 & 77,5194 & 1,4422 & 0,0469 & 0,0040 & 81,1 & 6,7 & 82,6 & 1,5 & n.c. & n.c. & 82,6 & 1,5 \\
\hline C-01-93 & 138,1 & 2,1 & 0,0749 & 0,0073 & 0,0111 & 0,0002 & 0,0005 & 90,0090 & 1,7824 & 0,0490 & 0,0050 & 72,4 & 6,9 & 71,2 & 1,4 & n.c. & n.c. & 71,2 & 1,4 \\
\hline C-01-94 & 428,0 & 1,4 & 2,0650 & 0,0280 & 0,1899 & 0,0014 & 0,3459 & 5,2659 & 0,0388 & 0,0788 & 0,0010 & 1136,1 & 9,4 & 1120,7 & 7,5 & 1164,0 & 25,0 & 1120,7 & 7,5 \\
\hline C-01-95 & 261,0 & 2,9 & 0,0849 & 0,0048 & 0,0135 & 0,0002 & 0,0237 & 73,9098 & 0,9833 & 0,0457 & 0,0026 & 82,4 & 4,5 & 86,6 & 1,2 & n.c. & n.c. & 86,6 & 1,2 \\
\hline C-01-96 & 244,6 & 1,7 & 0,0704 & 0,0051 & 0,0103 & 0,0003 & 0,2491 & 96,9932 & 2,8223 & 0,0501 & 0,0036 & 68,7 & 4,8 & 66,1 & 1,9 & n.c. & n.c. & 66,1 & 1,9 \\
\hline C-01-97 & 245,0 & 2,0 & 0,0829 & 0,0059 & 0,0127 & 0,0002 & 0,0581 & 78,7402 & 1,1160 & 0,0475 & 0,0034 & 80,3 & 5,5 & 81,3 & 1,1 & n.c. & n.c. & 81,3 & 1,1 \\
\hline C-01-98 & 147,1 & 2,1 & 0,0850 & 0,0081 & 0,0127 & 0,0002 & 0,0630 & 78,7402 & 1,4880 & 0,0487 & 0,0048 & 81,8 & 7,5 & 81,4 & 1,5 & n.c. & n.c. & 81,4 & 1,5 \\
\hline C-01-99 & 360,6 & 1,7 & 0,0819 & 0,0041 & 0,0128 & 0,0002 & 0,0274 & 78,0640 & 0,9750 & 0,0464 & 0,0023 & 80,1 & 3,9 & 82,0 & 1,0 & n.c. & n.c. & 82,0 & 1,0 \\
\hline C-01-100 & 293,2 & 1,4 & 0,3000 & 0,0120 & 0,0411 & 0,0004 & 0,3295 & 24,3191 & 0,2366 & 0,0528 & 0,0020 & 264,9 & 9,5 & 259,8 & 2,5 & 283,0 & 83,0 & 259,8 & 2,5 \\
\hline C-01-101 & 107,3 & 2,3 & 0,0883 & 0,0086 & 0,0137 & 0,0003 & 0,0644 & 72,8863 & 1,3812 & 0,0459 & 0,0045 & 84,7 & 8,0 & 87,8 & 1,6 & n.c. & n.c. & 87,8 & 1,6 \\
\hline C-01-102 & 553,0 & 3,0 & 1,8110 & 0,0300 & 0,1796 & 0,0015 & 0,5155 & 5,5679 & 0,0465 & 0,0734 & 0,0011 & 1050,0 & 10,0 & 1064,8 & 8,0 & 1019,0 & 30,0 & 1064,8 & 8,0 \\
\hline C-01-103 & 407,8 & 70,0 & 0,6570 & 0,0250 & 0,0793 & 0,0013 & 0,3189 & 12,6103 & 0,2067 & 0,0600 & 0,0022 & 511,0 & 16,0 & 491,6 & 8,0 & 601,0 & 74,0 & 491,6 & 8,0 \\
\hline
\end{tabular}




\section{Discusión}

\section{Localización del área fuente}

Los resultados de geocronología detrítica de la Formación Cimarrona, en especial la presencia de un grano de $66,1 \pm 1,9 \mathrm{Ma}$, confirma una edad de acumulación Maastrichtiana para esta unidad, como lo sugieren las observaciones paleontológicas publicadas (Gómez y Pedraza, 1994; Tchegliakova, 1996).

Una vez integradas las diferentes herramientas de análisis de procedencia, la identificación del área fuente incluye inicialmente la comparación con áreas actualmente expuestas. Sin embargo, la erosión, los procesos de traslación de bloques que dispersarían las áreas fuentes, y los cambios en la distribución espacio-temporal de las áreas emergidas deben ser evaluados cuando se busca conocer la paleogeografía de un orógeno como el Andino, caracterizado por la sobreimposición de fases orogénicas (revisión y referencias en Horton, 2018), o por los procesos de dispersión de bloques corticales asociados a la componente tectónica de rumbo (Montes et al., 2019).

El análisis de procedencia de las areniscas de la Formación Cimarrona, en especial la presencia de chert, lodolitas, metapsamitas y filitas, así como la moscovita, biotita y clorita en la fracción de minerales pesados, sugiere la presencia de rocas sedimentarias y metamórficas de bajo a muy bajo grado en el área fuente de esta unidad.

Las areniscas de ambos segmentos presentan un alto contenido de cuarzo, el cual se compone principalmente de granos monocristalinos con extinción ondulatoria y cuarzo policristalino. La abundancia de cuarzo policristalino de más de tres cristales de carácter foliado y difuso, incluyendo la presencia de líticos metamórficos y sedimentarios, así como el cuarzo con extinción ondulatoria sugiere fuentes sedimentarias y metamórficas de bajo grado (Basu et al., 1975; Young, 1976), las cuales estarían asociadas a la exposición de áreas fuente con niveles más superficiales de la corteza.

La presencia de una distribución bimodal en la redondez del cuarzo (redondeado y angular) igualmente estaría relacionada con aportes asociados al retrabajamiento de rocas sedimentarias clásticas, de las cuales se habría derivado el cuarzo más redondeado, en conjunto con aportes de primer ciclo relacionados con las rocas metamórficas de bajo grado de carácter metapsamítico con alto contenido de cuarzo, que podrían incluir venas o bandas de cuarzo, las cuales normalmente son comunes en el bajo a muy bajo grado de metamorfismo (Kisch, 1991).
Al comparar las características composicionales entre segmentos, se encuentran algunas diferencias, las cuales requieren algunas consideraciones especiales. El segmento más oriental $(\mathrm{Cc})$ de la unidad se caracteriza por una mayor proporción de líticos metamórficos (esquistos moscovíticos), y por la presencia de líticos volcánicos, los cuales no fueron reconocidos en el segmento Ca. Estas diferencias podrían estar relacionadas con cambios en el aporte entre ambos segmentos, en especial el aporte metamórfico que podría marcar la erosión inicial de los altos locales de basamento (ver más adelante), los cuales por su carácter de exposición más limitada estarían diluidos posteriormente por el predominio de fuentes sedimentarias.

Durante la compactación y cementación se pueden destruir los fragmentos volcánicos más inestables, en especial las partículas tobáceas (Remy, 1994; Khalaf, 2014). El carácter suturado de los contactos de los dos segmentos de la Formación Cimarrona confirma que estas rocas sufrieron un enterramiento significativo en el cual pudieron experimentar modificaciones importantes, afectando la proporción de los líticos menos resistentes de la armazón (como serían los líticos volcánicos) e incrementando la proporción de matriz. Sin embargo este efecto de ser controlador afectaría igualmente a los segmento Cc y $\mathrm{Ca}$, desapareciendo o disminuyendo la proporción de líticos. Podría considerarse en este sentido que la composición y textura de los líticos volcánicos podría variar entre ambos segmentos, pudiendo haber existido líticos menos resistentes a la diagénesis en el segmento $\mathrm{Ca}$, lo cual los destruiría más fácilmente.

La presencia de circones magmáticos del Cretácico Superior en el segmento $\mathrm{Ca}$, incluyendo edades próximas a la edad de acumulación, así como la presencia de apatito e incluso biotita, confirma que los aportes volcánicos fueron también importantes en este segmento. Por lo tanto, sin descartar el rol que la historia diagenética pudo causar, es posible que estos cambios composicionales se deban a un factor en el área de aporte que redujo la disponibilidad de otros fragmentos líticos más resistente, o eventualmente el desarrollo de una meteorización más intensa o inclusive el aporte de material volcánico muy fino con predominio de cenizas fácilmente modificable en el transporte, causaría la reducción del material lítico disponible para el transporte en el segmento Ca.

El cuarzo monocristalino con extinción recta y de carácter angular en ambos segmentos podría estar 
igualmente asociado a rocas magmáticas de primer ciclo. En efecto, en erupciones volcánicas se puede dar lugar a depósitos de ceniza con abundante cuarzo, los cuales durante la meteorización y el transporte podrían continuar su enriquecimiento como consecuencia de la inestabilidad del vidrio, formando así arenas ricas en cuarzo (Smyth et al., 2008; Morrone et al., 2017), que podrían igualmente ir acompañadas de los circones volcánicos resistentes a la meteorización. Por lo tanto mientras la variación en la proporción de las fases metamórficas podría estar asociado a cambios en el área de aporte, la variación en el tipo de material volcánico estaría dominada por otro tipo de procesos que modificaron los sedimentos.

Gómez y Pedraza (1994) discuten a partir del análisis de paleocorrientes y la presencia de líticos metamórficos en los conglomerados, que el área de aporte para la Formación Cimarrona se encontraba al occidente y correspondería a las rocas de una Cordillera Central ancestral. Los conteos de clastos de conglomerado realizados en esta contribución confirman la presencia de esquistos y rocas plutónicas afín con fuentes occidentales.

Los resultados de procedencia presentados en esta contribución confirman una fuente compatible con las rocas expuestas al occidente, mostrando algunas semejanzas con aquellas presentes en la Cordillera Central. Estos incluyen la presencia de líticos metamórficos, así como los circones magmáticos con edades del Cretácico Superior entre 70 y $83 \mathrm{Ma}$ (Figura 8C), los cuales trazan una fuente magmática característica de esta Cordillera, representada por la extensa provincia plutónica de esta edad que aflora en el segmento norte de la Cordillera (Figura 1). Estas rocas intruyen el basamento metamórfico de medio grado y granitoides de dos micas del Triásico o más viejos, así como los remanentes de rocas sedimentarias del Cretácico Inferior (e.g. Sedimentitas de San Luis, Amalfi y Berlín) (Ordóñez-Carmona y Pimentel, 2001; Leal-Mejía et al., 2019; Villagómez et al., 2011; DuqueTrujillo et al., 2019; Cardona et al., 2020), donde las rocas del Complejo Cajamarca y las Sedimentitas de San Luis presentan poblaciones de circones semejantes a la Formación Cimarrona, sugiriendo la erosión y reciclaje de esas unidades durante el Maastrichtiano (Figura 8D).

Adicionalmente, fuentes orientales o afines con la Cordillera Oriental o el Cratón de Guyana son descartadas por la diferencia entre los sustratos metamórficos sobre los que se acumulan las unidades sedimentarias. Mientras que al oriente el basamento ígneo y metamórfico es predominantemente de edad Paleozoico Inferior y Proterozoico (Horton et al., 2015), al occidente este incluye rocas entre el Carbonífero y el Jurásico (Spikings et al., 2015; Spikings y Paul, 2019; Rodríguez-García et al., 2019), semejantes a las documentadas en las edades detríticas.

La presencia de chert requiere una consideración especial, puesto que si bien este tipo de rocas son ampliamente distribuidas en el registro del Cretácico Superior de la Cordillera Oriental y el Valle del Magdalena (Villamil, 1999), en la Cordillera Central también es común encontrar en las secuencias del Cretácico una sedimentación acompañada de chert (Cardona et al., 2020). Esta ambigüedad geográfica limita por lo tanto su valor como trazador hasta que no se integre la observación petrográfica con análisis geoquímicos que permiten separar diferentes ambientes de acumulación del chert (Murray, 1994; Bruce y Percival, 2014; Garbán et al., 2017).

\section{Descapotamiento ("unroofing") del área fuente}

El registro de procedencia indica un predominio de fuentes sedimentarias y metamórficas de bajo grado, así como las fuentes magmáticas de carácter volcánico, lo que es igualmente sugerido por los diagramas de discriminación de Dickinson (1985) y Garzanti (2016), en los cuales las muestras analizadas se encuentran en el campo de los orógenos reciclados. En esta categoría, se incluyen orógenos en los que ocurre la erosión principalmente de coberteras sedimentarias durante la construcción de topografía en cadenas de montaña.

Este tipo de fuentes y el nivel estructural es diferente al que se observa actualmente en la Cordillera Central, donde predominan rocas metamórficas de medio-alto grado y rocas plutónicas (Figura 9C), mientras que las rocas metamórficas de bajo a muy bajo grado de metamorfismo y las rocas sedimentarias se encuentran expuestas de manera más limitada y discontinua (Figura 1 y 9C). Por lo tanto, se sugiere que durante la fase orogénica más temprana de la Cadena Andina, durante el Cretácico Superior, en el occidente estuvo expuesta la cobertera volcano-sedimentaria (Figura 9A y 9B), y que la exposición del basamento con una distribución litológica semejante al actual donde priman niveles estructurales relativamente más profundos tuvo lugar en las fases orogénicas posteriores. 

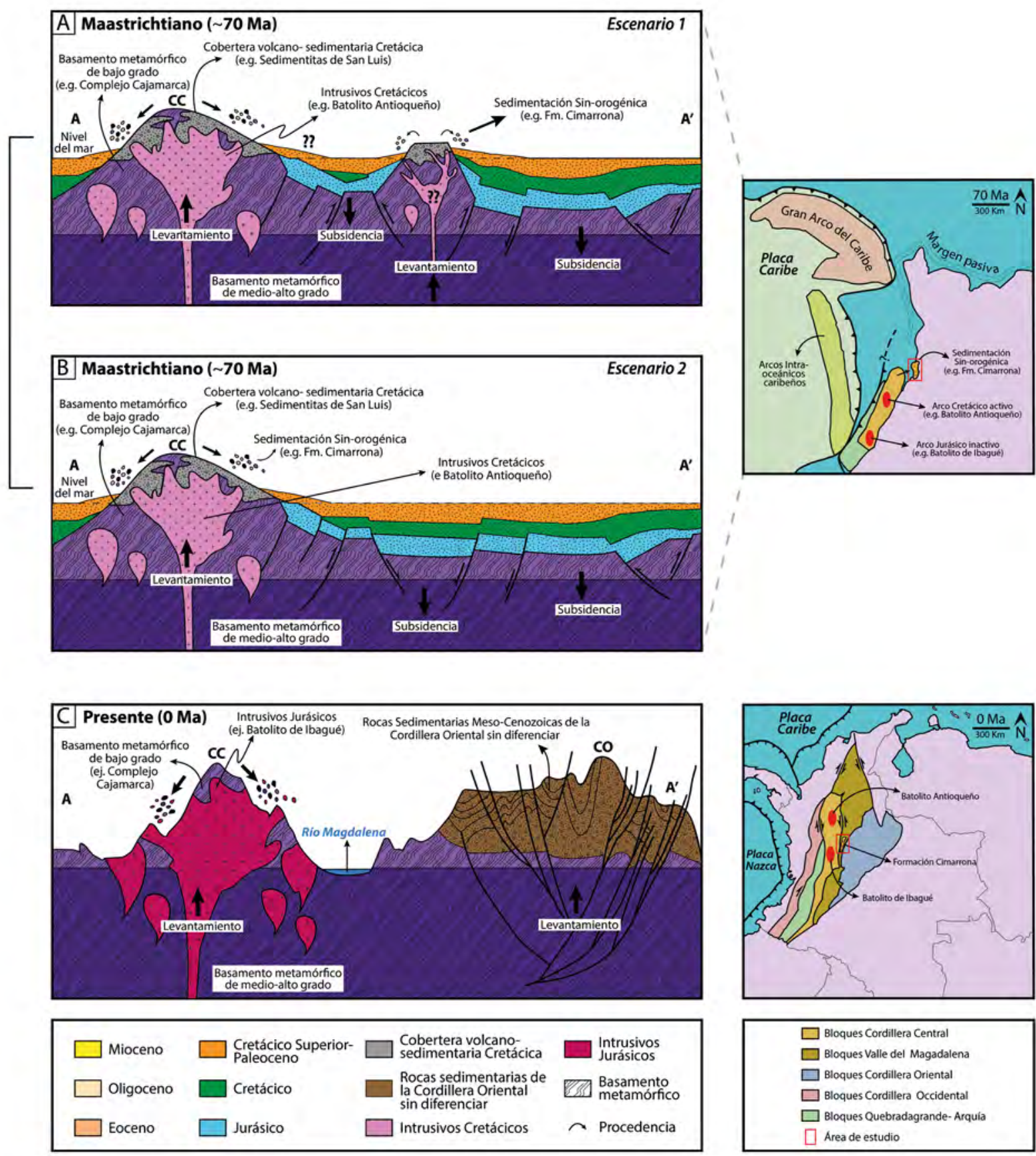

Figura 9. A. Esquema tectono-estratigráfico y reconstrucción paleogeográfica mostrando la posible configuración geológica de la margen occidental de los Andes del Norte en Colombia en el Maastrichtiano ( $70 \mathrm{Ma})$ con un alto de basamento como principal área fuente (escenario 1). B. Esquema tectono-estratigráfico y reconstrucción paleogeográfica mostrando la posible configuración geológica de la margen occidental de los Andes del Norte en Colombia en el Maastrichtiano ( $70 \mathrm{Ma})$ con una ancestral Cordillera marginal al occidente como principal área fuente (escenario 2). C. Configuración tectónica actual (0 Ma) de los Andes del Norte en Colombia a la latitud donde se encuentra expuesta la Formación Cimarrona, y distribución espacial de los bloques que componen los Andes del Norte en Colombia. Los esquemas son modificados de Villamil (1999), Caballero et al. (2013), Bayona (2018) y Montes et al. (2019). 
La persistencia de los líticos sedimentarios y el alto contenido de cuarzo, en conjunto con rocas cristalinas, sería una herencia de la geometría de las cuencas extensionales Cretácicas, donde los altos de basamento y las zonas de acumulación volcano-sedimentario estarían mezclados en el mismo nivel estructural (Zapata et al., 2019; Cardona et al., 2020). Algunas características composicionales semejantes a las documentadas en la Formación Cimarrona, incluyendo la presencia de líticos metamórficos, volcánicos y sedimentarios con cuarzo y poco feldespato, así como circones detríticos del Cretácico Superior, han sido documentadas en otras unidades sedimentarias clásticas del Maastrichtiano-Paleoceno (Umir y Lisama), cuya área fuente ha sido igualmente identificada al occidente (Caballero et al., 2013; Moreno et al., 2011; Nie et al., 2010, 2012; Lamus-Ochoa et al., 2013; Bayona, 2018), sugiriendo por lo tanto que regionalmente las áreas de aporte occidentales corresponden a niveles estructurales superiores, marcando la erosión de las coberteras sedimentarias (Bayona, 2018).

\section{Correlación con eventos termocronológicos}

Los resultados termocronológicos existentes para la Cordillera Central ofrecen, igualmente, algunos elementos para evaluar el patrón de denudación de niveles estructurales someros durante las fases tempranas de la orogenia Andina. Las trazas de fisión en circón y apatito y (U-Th)/He en circón en rocas cristalinas pre-Cenozoicas muestran edades de enfriamiento entre 85 y 60 Ma (Gómez et al., 2003; Villagómez y Spikings, 2013; Zapata et al., 2020). Estas edades podrían representar enfriamiento asociado a exhumación erosional o enfriamiento post-magmático. Si bien, en el Batolito Antioqueño se han documentado fases magmáticas de edad Cretácico tardío a Paleógeno (Leal-Mejía et al., 2019; Villagómez et al., 2011; Duque-Trujillo et al., 2019; Cardona et al., 2020), el limitado volumen y el nivel de emplazamiento somero cortando rocas sedimentarias Cretácicas podría no ser suficiente para reiniciar las edades del basamento (Murray et al., 2018), más cuando algunas de las muestras se encuentran lejos de unidades magmáticas Cretácicas (Figura 1). Por lo tanto, lo más probable es que el enfriamiento del basamento de la Cordillera Central estuviese relacionado a la erosión de niveles corticales superiores durante un periodo de levantamiento tectónico.

Recientemente, Zapata et al. (2020) presentaron nuevos datos de termocronología detrítica y de basamento usando los métodos de trazas de fisión y (U-Th)/He en circón. Estos nuevos datos combinados con la base de datos disponible sugieren que este segmento de la Cordillera Central experimentó un fuerte periodo de exhumación entre el Cretácico tardío y el Paleoceno, además se propone que esta exhumación estuvo asociada a la erosión de una cobertera volcanosedimentaria que pudo haber tenido entre $\sim 4 \mathrm{~km}$ y 5 $\mathrm{km}$ de espesor. Los datos presentados en este trabajo confirman esta hipótesis.

La muestra DV82 presentada en Villagómez y Spikings (2013) es ideal para cuantificar exhumación durante el Cretácico Superior-Paleoceno ya que: (1) corresponde a un intrusivo de edad de cristalización Pérmica, con una edad ${ }^{40} \mathrm{Ar} /{ }^{39} \mathrm{Ar}$ de $\sim 113 \mathrm{Ma}$, (2) preserva datos de trazas de fisión en circón $(\sim 78 \mathrm{Ma})$ y apatito $(\sim 68$ Ma) del Cretácico Superior, y (3) está localizada $\sim 200$ $\mathrm{km}$ al sur de los cuerpos magmáticos Cretácicos, y al sur del estudio presentado por Zapata et al. (2020). Para esta muestra, los autores presentan un modelo termal que sugiere un enfriamiento de al menos $140^{\circ} \mathrm{C}$ entre $\sim 80$ Ma y $65 \mathrm{Ma}$, lo cual equivale a un evento de exhumación entre $\sim 3,7 \mathrm{~km}$ y $5,2 \mathrm{~km}$, si asumimos gradientes geotermales normales para corteza continental entre 25 y $35^{\circ} \mathrm{C} / \mathrm{km}$ y una temperatura superficial de $10^{\circ} \mathrm{C}$.

Los datos termocronológicos publicados sugieren la existencia de un importante evento de exhumación durante el Cretácico Superior-Paleoceno, en el cual se removió una cobertera sedimentaria de hasta $4 \mathrm{~km}$ de espesor (Zapata et al., 2020), además la distribución de las edades de enfriamiento del Cretácico Superior, sugieren que este evento de exhumación involucró todo el segmento norte de la Cordillera Central (Villagómez y Spikings 2013; Zapata et al., 2020). Este episodio estaría igualmente asociado al enfriamiento de las rocas localizadas en niveles corticales más profundos; las cuales serían las que hoy están expuestas en la Cordillera Central. Los niveles corticales más someros serían la principal área de aporte de la Formación Cimarrona y de otras unidades clásticas del Cretácico Superior-Paleoceno.

En el Maastrichtiano el nivel eustático del mar y la subsidencia tectónica se incrementaban, por lo tanto, la somerización de los sistemas depositacionales responsables de la acumulación de la Formación Cimarrona estaría relacionada con un incremento drástico del suministro de sedimentos, concomitante con un evento de exhumación en la Cordillera Central (Gómez et al., 2003), el cual debió estar asociado a una fase de levantamiento tectónico de la corteza de 
carácter más regional; de lo contrario un aumento del nivel del mar a nivel global y una tasa de subsidencia tectónica mayor, generarían ambientes más profundos.

\section{Movimientos de rumbo}

Un mapa de sub-afloramiento bajo la discordancia del Eoceno medio del Valle Medio del Magdalena, el cual fue construido con base en datos de pozos y sísmica de reflexión, documenta la presencia de altos de basamento y semi-grábenes del JurásicoCretácico yaciendo discordantemente bajo la sucesión sedimentaria Cenozoica (Caballero et al., 2013). Estos elementos confirman la existencia de una topografía del Cretácico Superior al Eoceno, que incluye tanto el Valle Medio del Magdalena como algunos segmentos de la Cordillera Central, los cuales habrían sido erosionados, cuyos productos quedarían acumulados en el registro sedimentario como el de la Formación Cimarrona. El registro de abanico deltaico de la Formación Cimarrona hace parte de sistemas terrígenos discontinuos, en los cuales lateralmente a pocos kilómetros se acumularon sistemas carbonatados $\mathrm{y}$ de fondos marinos lodosos (Guerrero et al., 2000; Gómez et al., 2003; Bayona, 2018). Esta configuración contrasta con el aparente carácter continuo de la sedimentación clástica contemporánea en las cuencas sedimentarias occidentales que hoy hacen parte la Cordillera Occidental colombiana (González, 2001; Nivia, 2001; León et al., 2018), sugiriendo por lo tanto que el crecimiento cordillerano oriental de los Andes del Norte durante el inicio de la orogenia Andina está marcado por diferentes bloques emergidos (Bayona, 2018), los cuales habrían sido erosionados y sepultados probablemente en el Valle del Magdalena (Caballero et al., 2013), y podrían tener características litoestratigráficas semejantes a las presentes en la Cordillera Central. Por lo tanto, se sugiere que el relleno de la Formación Cimarrona podría estar relacionado a la denudación de los niveles corticales superiores de un dominio semejante a la Cordillera Central o un alto de basamento expuesto en el Valle del Magdalena los cuales tendrían las mismas características geológicas (Figura 9).

A pesar de que la presencia de clastos magmáticos del Cretácico superior y de rocas metasedimentarias es afín en términos generales con fuentes al occidente, en la Cordillera Central, la combinación de estas dos litologías no coincide exactamente con las rocas expuestas actualmente en una posición geográfica inmediatamente al occidente del segmento donde se encuentra expuesta la Formación Cimarrona, ya que en esta región la Cordillera Central y el Valle del Magdalena predominan rocas magmáticas y metamórficas del Jurásico a Cretácico Inferior asociadas a rocas cristalinas también del Triásico y el Pérmico (Bustamante et al., 2016, 2017; Rodríguez-García et al., 2019, Figura 1 y 9). Sin embargo, inmediatamente al noroccidente del área de exposición de la Formación Cimarrona, como continuación estructural de las rocas magmáticas Jura-Cretácicas mencionadas, afloran en la Cordillera Central los remanentes de rocas sedimentarias del Cretácico Inferior (Formación San Luis) intruídas por el Batolito Antioqueño. Tanto la Formación San Luis, como el Batolito Antioqueño, presentan poblaciones de circones detríticos semejantes a los reconocidos en la Formación Cimarrona (Figura 1 y $8 \mathrm{D}$ ). La distribución de facies regional para este intervalo de tiempo (Bayona, 2018), sugiere que al noroccidente del área de estudio no había un relieve positivo, apoyando la idea de que las áreas fuente de la Formación Cimarrona efectivamente fueron desplazadas hacia el norte por movimientos laterales de rumbo.

Dos posibles escenarios geológicos podrían explicar este desacoplamiento actual entre el área fuente y la cuenca, manteniendo el área de aporte occidental previamente discutida. (1) La historia geológica sobreimpuesta, incluyendo la erosión, habría llevado a la erosión de una extensa área fuente magmática Cretácica. (2) Desplazamientos de rumbo hacia el norte, probablemente a través del sistema de fallas de Palestina u Otú-Pericos (Feininger, 1970; Acosta et al., 2007; Montes et al., 2019; Zapata et al., 2019), habrían aislado el área fuente de su cuenca adyacente.

El análisis global de la distribución espacial de la actividad magmática en márgenes convergentes ha mostrado que los arcos magmáticos se distribuyen por segmentos discontinuos, en los cuales se alternan nidos con zonas activas y zonas carentes de actividad magmática, reflejando una geometría de dedos calientes (hot fingers) que concentran de forma discontinua la generación de magmas (Tamura et al., 2002). Esta situación de hecho se observa actualmente en las provincias volcánicas activas de los Andes Colombianos, donde existen segmentos que carecen de registro magmático separando las zonas con vulcanismo activo.

Por esta razón es posible sugerir que la erosión no explica el desacoplamiento cuenca-área fuente y por lo tanto se sugiere que el área fuente de la Formación Cimarrona localizada al occidente, habría sido 
transportada al norte probablemente a lo largo de las fallas expuestas entre la Codillera Central y el Valle del Magdalena, como consecuencia de la importante componente de rumbo que afectó la tectónica Cenozoica de los Andes del Norte (Montes et al., 2019). En este sentido, Lamus-Ochoa et al. (2013) documentaron en las unidades Eocenas de la zona central del Sinclinal de Guaduas, cerca del municipio de Honda (Tolima) a la latitud de $5^{\circ} \mathrm{N}$ aproximadamente, poblaciones de circón semejantes a las identificadas en la Formación Cimarrona, seguidas en el Oligoceno de un cambio a fuentes con circones Jurásicos más afín con las rocas expuestas actualmente al occidente, sugiriendo por lo tanto que los desplazamientos de rumbo ocurrieron principalmente entre el Eoceno y el Oligoceno. Si bien el análisis de la cinemática de la margen continental y sus controles se encuentra por fuera del alcance de este estudio, la aparente estabilidad de áreas fuentes entre el Maastrichtiano y el Eoceno sugiere que los desplazamientos de rumbo no serían continuos, sino que reflejan una historia más episódica, detonada en el Eoceno Superior-Oligoceno cuando la margen continental aparentemente estaba dominado por una convergencia extremadamente oblicua (Bayona et al., 2012; Montes et al., 2019).

\section{Conclusiones}

La presencia de líticos volcánicos $\mathrm{y} / \mathrm{o}$ circones detríticos del Cretácico Superior, incluyendo una población tan joven como $66,1 \pm 1,9$ Ma sugiere que la acumulación de la Formación Cimarrona estuvo relacionada con un vulcanismo contemporáneo a la sedimentación. Además, estarían indicando que el extenso plutonismo de esa edad actualmente expuesto en la Cordillera Central tuvo un equivalente volcánico que habría sido erosionado.

Las características petrográficas incluyendo la presencia de líticos sedimentarios, metamórficos de bajo a medio grado y líticos volcánicos, las edades termocronológicas de la Cordillera Central, las poblaciones de edades en circones detríticos, y las paleocorrientes documentadas por Gómez y Pedraza (1994), sugieren que el material clástico de la Formación Cimarrona sería el resultado de la denudación de las coberturas volcánicas y sedimentarias Cretácicas que habrían cubierto previamente el basamento de la Cordillera Central, o bien, de altos estructurales en la cuenca del Magdalena. Por lo tanto, la exposición del nivel estructural actual de esta Cordillera, donde predominan rocas metamórficas de medio-alto grado y rocas plutónicas, es el resultado de eventos posteriores de exhumación-levantamiento-erosión.

El carácter discontinuo de los sistemas de abanico deltaico como los de la Formación Cimarrona podrían estar asociados a la existencia de altos separados de la Cordillera Central que estarían actualmente sepultados en el Valle del Río Magdalena.

El área fuente más probable para la Formación Cimarrona se encuentra en un sector más noroccidental de la Cordillera Central a la altura del Departamento de Antioquia, sugiriéndose por lo tanto que esta configuración actual es el resultado de desplazamientos posteriores de rumbo del segmento topográfico occidental.

\section{Agradecimientos}

Los autores agradecemos el apoyo del proyecto 15686 de COLCIENCIAS, así como las continuas discusiones paleogeográficas y de procedencia con Camilo Montes y los integrantes del Grupo de Estudios en Geología y Geofísica (EGEO) de la Universidad Nacional de Colombia, Sede Medellín. Adicionalmente agradecemos enormemente los comentarios y sugerencias de Mauricio Parra y Yamirka Rojas que contribuyeron enormemente a aclarar la presentación y discusión coherente de los resultados presentados en el manuscrito.

\section{Referencias}

Acosta, J.; Velandia, F.; Osorio, J.; Lonergan, L.; Mora, H. (2007). Strike-slip deformation within the Colombian Andes. Geological Society, London, Special Publication, 272, 303-319. https://doi. org/10.1144/GSL.SP.2007.272.01.16

Avellaneda-Jiménez, D.S.; Cardona, A.; Valencia, V.; Barbosa, J.S.; Jaramillo, J.S.; Monsalve, G.; Ramírez-Hoyos, L. (2020). Erosion and regional exhumation of an Early Cretaceous subduction/ accretion complex in the Northern Andes. International Geology Review, 62(2), 186-209. https://doi.org/10.1080/00206814.2019.1596042

Ayala, R.C.; Bayona, G.; Cardona, A.; Ojeda, C.; Montenegro, O.C.; Montes, C.; Valencia, V.; Jaramillo, C. (2012). The paleogene synorogenic succession in the northwestern Maracaibo 
block: Tracking intraplate uplifts and changes in sediment delivery systems. Journal of South American Earth Sciences, 39, 93-111. https://doi. org/10.1016/j.jsames.2012.04.005

Ballesteros-Torres, C.I.; Galvis-Portilla, H.A.; Higuera-Díaz, I.C.; Marfisi, N.K.; de la Parra, F.; Céspedes, S.; Cantisano, M.T.; Forero, S.P.; Barrera, P.A.; Rodríguez, C.E.; Zamora, W.H.; Restrepo, D.P.; Cerón, J.; Castillo, R.D. (2013). Anotaciones acerca de la estratigrafía del intervalo Cenomaniano-Campaniano atravesado por el pozo La Luna-1, cuenca Valle Medio del Magdalena. XIV Congreso Colombiano de Geología, Bogotá, Colombia.

Basu, A.; Young, S.W.; Suttner, L.J.; James, W.C.; Mack, G.H. (1975). Re-evaluation of the use of undulatory extinction and polycrystallinity in detrital quartz for provenance interpretation. Journal of Sedimentary Research, 45(4), 873882. https://doi.org/10.1306/212F6E6F-2B2411D7-8648000102C1865D

Bayona, G. (2018). El inicio de la emergencia de los Andes del norte: una perspectiva a partir del registro tectónico-sedimentológico del Coniaciano al Paleoceno. Revista de La Academia Colombiana de Ciencias Exactas, Físicas $y$ Naturales, 42(165), 364-378. https://doi. org/10.18257/raccefyn. 632

Bayona, G.; Cardona, A.; Jaramillo, C.; Mora, A.; Montes, C.; Valencia, V.; Ayala, C.; Montenegro, O.; Ibañez-Mejia, M. (2012). Early Paleogene magmatism in the northern Andes: Insights on the effects of Oceanic Plateau-continent convergence. Earth and Planetary Science Letters, 331-332, 97111. https://doi.org/10.1016/j.epsl.2012.03.015

Bayona, G.; Cardona, A.; Jaramillo, C.; Mora, A.; Montes, C.; Caballero, V.; Mahecha, H.; Lamus, F.; Montenegro, O.; Jimenez, G.; Mesa, A.; Valencia, V. (2013). Onset of fault reactivation in the Eastern Cordillera of Colombia and proximal Llanos Basin; response to Caribbean-South American convergence in early Palaeogene time. Geological Society, London, Special Publications, 377, 285-314. https://doi.org/10.1144/SP377.5

Blanco-Quintero, I.F.; García-Casco, A.; Toro, L.M.; Moreno, M.; Ruiz, E.C.; Vinasco, C.J.; Cardona, A.; Lázaro, C.; Morata, D. (2014). Late Jurassic terrane collision in the northwestern margin of Gondwana (Cajamarca Complex, eastern flank of the Central Cordillera, Colombia). International Geology Review, 56(15), 1852-1872. https://doi. org/10.1080/00206814.2014.963710

Boschman, L.M.; van Hinsbergen, D.J.J.; Torsvik, T.H.; Spakman, W.; Pindell, J.L. (2014). Kinematic reconstruction of the Caribbean region since the Early Jurassic. Earth-Science Reviews, 138, 102-136. https://doi.org/10.1016/j. earscirev.2014.08.007

Bruce, M.C.; Percival, I.G. (2014). Geochemical evidence for provenance of Ordovician cherts in southeastern Australia. Australian Journal of Earth Sciences, 61(7), 927-950. https://doi.org/1 $0.1080 / 08120099.2014 .956792$

Bustamante, C.; Cardona, A.; Bayona, G.; Mora, A.; Valencia, V.; Gehrels, G.; Vervoort, J. (2010). $\mathrm{U}-\mathrm{Pb}$ LA-ICP-MS geochronology and regional correlation of Middle Jurassic intrusive rocks from the Garzon Massif, Upper Magdalena Valley and Central Cordillera, southern Colombia. Boletín de Geología, 32(2), 93-109.

Bustamante, C.; Archanjo, C.J.; Cardona, A.; Vervoort, J.D. (2016). Late Jurassic to Early Cretaceous plutonism in the Colombian Andes: A record of long-term arc maturity. GSA Bulletin, 128(11-12), 1762-1779. https://doi.org/10.1130/B31307.1

Bustamante, C.; Archanjo, C.J.; Cardona, A.; Bustamante, A.; Valencia, V.A. (2017). U-Pb ages and $\mathrm{Hf}$ isotopes in zircons from parautochthonous Mesozoic terranes in the western margin of Pangea: Implications for the terrane configurations in the northern Andes. The Journal of Geology, 125(5), 487-500. https://doi.org/10.1086/693014

Caballero, V.; Parra, M.; Mora, A.; López, C.; Rojas, L.E.; Quintero, I. (2013). Factors controlling selective abandonment and reactivation in thickskin orogens: a case study in the Magdalena Valley, Colombia. Geological Society, London, Special Publications, 377, 343-367. https://doi. org/10.1144/SP377.4

Cardona, A.; Valencia, V.; Lotero, A.; Villafañez, Y.; Bayona, G. (2016). Provenance of middle to late Palaeozoic sediments in the northeastern Colombian Andes: implications for Pangea 
reconstruction. International Geology Review, 58(15), 1914-1939. https://doi.org/10.1080/0020 6814.2016.1190948

Cardona, A.; León, S.; Jaramillo, J.S.; Valencia, V.; Zapata, S.; Pardo-Trujillo, A.; Schmitt, A.K.; Mejía, D.; Arenas, J.C. (2020). Cretaceous record from a Mariana- to an Andean-type margin in the Central Cordillera of the Colombian Andes. In: J. Gómez; A.O. Pinilla-Pachon (eds.). The Geology of Colombia (pp. 353-395). Vol. 2, Chapter 10. Servicio Geológico Colombiano. https://doi. org/10.32685/pub.esp.36.2019.10

Chang, Z.; Vervoort, J.D.; McClelland, W.C.; Knaack, C. (2006). U-Pb dating of zircon by LA-ICP-MS. Geochemistry, Geophysics, Geosystems, 7(5). https://doi.org/10.1029/2005GC001100

Cheng, F.; Jolivet, M.; Fu, S.; Zhang, C.; Zhang, Q.; Guo, Z. (2016). Large-scale displacement along the Altyn Tagh Fault (North Tibet) since its Eocene initiation: Insight from detrital zircon $\mathrm{U}-\mathrm{Pb}$ geochronology and subsurface data. Tectonophysics, 677-678, 261-279. https://doi. org/10.1016/j.tecto.2016.04.023

Cochrane, R. (2013). U-Pb thermochronology, geochronology and geochemistry of NW South America: Rift to drift transition, active margin dynamics and implications for the volume balance of continents. PhD. Thesis, Université de Genève, Switzerland.

Cochrane, R.; Spikings, R.A.; Gerdes, A.; Ulianov, A.; Mora, A.; Villagómez, D.; Putlitz, B.; Chiaradia, M. (2014a). Permo-Triassic anatexis, continental rifting and the disassembly of western Pangaea. Lithos, 190-191, 383-402. https://doi. org/10.1016/j.lithos.2013.12.020.

Cochrane, R.; Spikings, R.; Gerdes, A.; Winkler, W.; Ulianov, A.; Mora, A.; Chiaradia, M. (2014b). Distinguishing between in-situ and accretionary growth of continents along active margins. Lithos, 202-203, 382-394. https://doi.org/10.1016/j. lithos.2014.05.031

Copeland, P. (2020). On the use of geochronology of detrital grains in determining the time of deposition of clastic sedimentary strata. Basin Research. https://doi.org/10.1111/bre.12441
Cordani, U.G.; Cardona, A.; Jimenez, D.M.; Liu, D.; Nutman, A.P. (2005). Geochronology of Proterozoic basement inliers in the Colombian Andes: tectonic history of remnants of a fragmented Grenville belt. Geological Society, London, Special Publications, 246, 329-346. https://doi.org/10.1144/GSL.SP.2005.246.01.13

Cortés, M.; Colleta, B.; Angelier, J. (2006). Structure and tectonics of the central segment of the Eastern Cordillera of Colombia. Journal of South American Earth Sciences, 21(4), 437-465. https:// doi.org/10.1016/j.jsames.2006.07.004

De Porta, J. (1965). La estratigrafía del Cretácico superior y terciario en el extremo $\mathrm{S}$ del Valle Medio del Magdalena. Boletín de Geología, 19, 5-50.

De Porta, J. (1966). Geología del extremo S del Valle Medio del Magdalena entre Honda y Guataquí (Colombia). Boletín de Geología, 22-23, 5-341.

DeCelles, P.G.; Carrapa, B.; Horton, B.K.; Gehrels, G.E. (2011). Cenozoic foreland basin system in the central Andes of northwestern Argentina: implications for Andean geodynamics and modes of deformation. Tectonics, 30(6). https://doi. org/10.1029/2011TC002948

Dickinson, W.R. (1970). Interpreting detrital modes of graywacke and arkose. Journal of Sedimentary Research, 40(2), 695-707. https:// doi.org/10.1306/74D72018-2B21-11D7$8648000102 \mathrm{C} 1865 \mathrm{D}$

Dickinson, W.R.; Suczek, C.A. (1979). Plate tectonics and sandstone compositions. AAPG Bulletin, 63(12), 2164-2182. https:// doi.org/10.1306/2F9188FB-16CE-11D7$8645000102 \mathrm{C} 1865 \mathrm{D}$

Dickinson, W.R. (1985). Interpreting provenance relations from detrital modes of Sandstones. In: G.G. Zuffa (Ed.). Provenance of Arenites (pp. 333-361). Vol. 148. Springer.

Dickinson, W.R.; Gehrels, G.E. (2009). Use of $\mathrm{U}-\mathrm{Pb}$ ages of detrital zircons to infer maximum depositional ages of strata: A test against a Colorado Plateau Mesozoic database. Earth and Planetary Science Letters, 288(1-2), 115-125. https://doi.org/10.1016/j.epsl.2009.09.013 
Dorsey, R.J. (1988). Provenance evolution and unroofing history of a modern arc-continent collision; evidence from petrography of PlioPleistocene sandstones, eastern Taiwan. Journal of Sedimentary Research, 58(2), 208-218. https://doi.org/10.1306/212F8D5A-2B24-11D7$8648000102 \mathrm{C} 1865 \mathrm{D}$

Draut, A.E.; Clift, P.D. (2012). Basins in arc-continent collisions. In: C. Busby; A. Azor (eds.). Tectonics of Sedimentary Basins: Recent Advances (pp. 347-368). Wiley-Blackwell.

Duque-Trujillo, J.; Bustamante, C.; Solari, L.; Gómez-Mafla, A.; Toro-Villegas, G.; Hoyos, S. (2019). Reviewing the Antioquia batholith and satellite bodies: a record of Late Cretaceous to Eocene syn- to post-collisional arc magmatism in the Central Cordillera of Colombia. Andean Geology, 46(1), 82-101. https://doi.org/10.5027/ andgeoV46n1-3120

Elrich, R.N.; Villamil, T.; Keens-Dumas, J. (2003). Controls on the deposition of Upper Cretaceous organic carbon-rich rocks from Costa Rica to Suriname. In: C. Bartolini, R.T. Buffler, J. Blickwede (Eds.). The Circum-Gulf of Mexico and the Caribbean: Hydrocarbon habitats, basin formation, and plate tectonics (pp. 1-45). AAPG Memoir, Vol. 79.

Etayo, F.; Renzoni, G.; Barrero, D. (1976). Contornos sucesivos del mar Cretácico en Colombia. I Congreso Colombiano de Geología. Bogotá, Colombia.

Feininger, T. (1970). The Palestina Fault, Colombia. GSA Bulletin, 81(4), 1201-1216. https://doi. org/10.1130/0016-7606(1970)81[1201:TPFC]2.0 . $\mathrm{CO} ; 2$

Folk, R.L. (1980). Petrology of Sedimentary Rocks. Hemphill Publishing Company.

Garbán, G.; Martínez, M.; Márquez, G.; Rey, O.; Escobar, M.; Esquinas, N. (2017). Geochemical signatures of bedded cherts of the upper La Luna Formation in Táchira State, western Venezuela: Assessing material provenance and paleodepositional setting. Sedimentary Geology, 347, 130-147. https://doi.org/10.1016/j. sedgeo.2016.11.001
Garzanti, E.; Vezzoli, G. (2003). A classification of metamorphic grains in sands based on their composition and grade. Journal of Sedimentary Research, 73(5), 830-837. https://doi. org/10.1306/012203730830

Garzanti, E.; Vezzoli, G.; Lombardo, B.; Andò, S.; Mauri, E.; Monguzzi, S.; Russo, M. (2004). Collision-orogen provenance (Western Alps): detrital signatures and unroofing trends. The Journal of Geology, 112(2), 145-164. https://doi. org/10.1086/381655

Garzanti, E.; Doglioni, C.; Vezzoli, G.; Andò, S. (2007). Orogenic belts and orogenic sediment provenance. The Journal of Geology, 115(3), 315334. https://doi.org/10.1086/512755

Garzanti, E. (2016). From static to dynamic provenance analysis - Sedimentary petrology upgraded. Sedimentary Geology, 336, 3-13. https://doi. org/10.1016/j.sedgeo.2015.07.010

Gehrels, G.; Valencia, V.; Pullen, A. (2006). Detrital zircon geochronology by laserablation Multicollector ICPMS at the Arizona LaserChron Center. The Paleontological Society Papers, 12, 67-76. https://doi.org/10.1017/ S1089332600001352

Gómez, E.; Pedraza, P. (1994). El Maastrichtiano de la región de Honda - Guaduas, límite norte del Valle superior del Magdalena: Registro sedimentario de un delta dominado por ríos trenzados. En: F. Etayo-Serna (ed.). Estudios geológicos del Valle Superior del Magdalena (pp. III1-III20). Universidad Nacional de Colombia.

Gómez, E.; Jordan, T.E.; Allmendinger, R.W.; Hegarty, K.; Kelley, S.; Heizler, M. (2003). Controls on architecture of the Late Cretaceous to Cenozoic southern Middle Magdalena Valley Basin, Colombia. GSA Bulletin, 115(2), 131-147. https:// doi.org/10.1130/0016-7606(2003)115<0131:CO AOTL $>2.0 . C O ; 2$

González, H. (2001). Mapa geológico del Departamento de Antioquia. Escala 1:400.000. Memoria Explicativa. INGEOMINAS, Medellín, Colombia.

Guerrero, J.; Sarmiento, G.; Navarrete, R.E. (2000). The stratigraphy of the $\mathrm{W}$ side of the Cretaceous 
Colombian Basin in the Upper Magdalena Valley. Reevaluation of selected areas and type localities including Aipe, Guaduas, Ortega, and Piedras. Geología Colombiana, 25, 45-110.

Herriott, T.M.; Crowley, J.L.; Schmitz, M.D.; Wartes, M.A.; Gillis, R.J. (2019). Exploring the law of detrital zircon: LA-ICP-MS and CA-TIMS geochronology of Jurassic forearc strata, Cook Inlet, Alaska, USA. Geology, 47(11), 1044-1048. https://doi.org/10.1130/G46312.1

Hincapié-Gómez, S.; Cardona, A.; Jiménez, G.; Monsalve, G.; Ramírez-Hoyos, L.; Bayona, G. (2018). Paleomagnetic and gravimetrical reconnaissance of Cretaceous volcanic rocks from the Western Colombian Andes: Paleogeographic connections with the Caribbean Plate. Studia Geophysica et Geodaetica, 62(3), 485-511. https://doi.org/10.1007/s11200-016-0678-y

Horton, B.K. (2018). Sedimentary record of Andean mountain building. Earth-Science Reviews, $178, \quad 279-309$. https://doi.org/10.1016/j. earscirev.2017.11.025

Horton, B.K.; Anderson, V.J.; Caballero, V.; Saylor, J.E.; Nie, J.; Parra, M.; Mora, A. (2015). Application of detrital zircon $\mathrm{U}-\mathrm{Pb}$ geochronology to surface and subsurface correlations of provenance, paleodrainage, and tectonics of the Middle Magdalena Valley Basin of Colombia. Geosphere, 11(6), 1790-1811. https://doi. org/10.1130/GES01251.1

Horton, B.K.; Parra, M.; Saylor, J.E.; Nie, J.; Mora, A.; Torres, V.; Stockli, D.F.; Strecker, M. (2010). Resolving uplift of the northern Andes using detrital zircon age signatures. GSA Today, 20(7), 4-10. https://doi.org/10.1130/GSATG76A.1

Ibáñez-Mejía, M.; Tassinari, C.C.G.; Jaramillo-Mejía, J.M. (2007). U-Pb zircon ages of the "Antioquian Batholith": geochronological constraints of Late Cretaceous magmatism in the Central Andes of Colombia. XI Congreso Colombiano de Geología, Bucaramanga, Colombia.

Ibañez-Mejia, M.; Ruiz, J.; Valencia, V.; Cardona, A.; Gehrels, G.E.; Mora, A.R. (2011). The Putumayo Orogen of Amazonia and its implications for Rodinia reconstructions: New U-Pb geochronological insights into the Proterozoic tectonic evolution of northwestern South America. Precambrian Research, 191(1-2), 58-77. https:// doi.org/10.1016/j.precamres.2011.09.005

Ingersoll, R.V.; Bullard, T.F.; Ford, R.L.; Grimm, J.P.; Pickle, J.D.; Sares, S.W. (1984). The effect of grain size on detrital modes: a test of the GazziDickinson point-counting method. Journal of Sedimentary Research, 54(1), 103-116. https:// doi.org/10.1306/212F83B9-2B24-11D7$8648000102 \mathrm{C} 1865 \mathrm{D}$

Jaramillo, J.S.; Cardona, A.; León, S.; Valencia, V.; Vinasco, C. (2017). Geochemistry and geochronology from Cretaceous magmatic and sedimentary rocks at $6^{\circ} 35^{\prime} \mathrm{N}$, western flank of the Central cordillera (Colombian Andes): Magmatic record of arc-growth and collision. Journal of South American Earth Sciences, 76, 460-481. https://doi.org/10.1016/j.jsames.2017.04.012

Kerr, A.C.; Marriner, G.F.; Tarney, J.; Nivia, A.; Saunders, A.D.; Thirlwall, M.F.; Sinton, C.W. (1997). Cretaceous Basaltic Terranes in Western Colombia: Elemental, Chronological and $\mathrm{Sr}$ - Nd Isotopic Constraints on Petrogenesis. Journal of Petrology, 38(6), 677-702. https://doi. org/10.1093/petrology/38.6.677

Khalaf, E.E.D.A.H. (2014). Diagenetic evolution of the volcaniclastic deposits: an example from Neoproterozoic Dokhan Volcanics in Wadi Queih basin, central Eastern Desert, Egypt. Arabian Journal of Geosciences, 7(7), 2603-2624. https:// doi.org/10.1007/s12517-013-0910-9

Kisch, H.J. (1991). Development of slaty cleavage and degree of very-low-grade metamorphism: a review. Journal of Metamorphic Geology, 9(6), 735750. https://doi.org/10.1111/j.1525-1314.1991. tb00562.x

Lamus-Ochoa, F.; Bayona, G.; Cardona, A.; Mora, A. (2013). Procedencia de las unidades Cenozoicas del Sinclinal de Guaduas: implicación en la evolución tectónica del sur del Valle Medio del Magdalena y orógenos adyacentes. Boletín de Geología, 35(1), 17-42.

Leal-Mejía, H. (2011). Phanerozoic gold metallogeny in the Colombian Andes: A tectono-magmatic approach. PhD. Thesis, Universidad de Barcelona, España. 
Leal-Mejía, H.; Shaw, R.P.; Melgarejo, J.C. (2019). Spatial-temporal migration of granitoid magmatism and the Phanerozoic tectonomagmatic evolution of the Colombian Andes. In: F. Cediel; R.P. Shaw (Eds.). Geology and tectonics of northwestern South America (pp. 253-410). Springer, Cham.

León, S.; Cardona, A.; Parra, M.; Sobel, E.R.; Jaramillo, J.S.; Glodny, J.; Valencia, V.; Chew, D.; Montes, C.; Posada, G.; Monsalve, G.; PardoTrujillo, A. (2018). Transition from collisional to subduction-related regimes: an example from Neogene Panama-Nazca-South-America interactions. Tectonics, 37(1), 119-139. https:// doi.org/10.1002/2017TC004785

Ludwig, K. (2007). User's manual for Isoplot 3.7. Berkley, Berkley Geochronology Center, p. 70.

Mange, M.A.; Maurer, H.F.W. (1992). Heavy minerals in color. Chapman \& Hall.

Mantilla-Figueroa, L.C.; Bissig, T.; Valencia, V.; Hart, C.J.R. (2013). The magmatic history of the VetasCalifornia mining district, Santander Massif, Eastern Cordillera, Colombia. Journal of South American Earth Sciences, 45, 235-249. https:// doi.org/10.1016/j.jsames.2013.03.006

Montes, C.; Hatcher Jr, R.D.; Restrepo-Pace, P.A. (2005). Tectonic reconstruction of the northern Andean blocks: Oblique convergence and rotations derived from the kinematics of the Piedras-Girardot area, Colombia. Tectonophysics, 399(1-4), 221-250. https://doi.org/10.1016/j. tecto.2004.12.024

Montes, C.; Rodríguez-Corcho, A.F.; Bayona, G.; Hoyos, N.; Zapata, S.; Cardona, A. (2019). Continental margin response to the multiple arc-continent collisions: The northern AndesCaribbean margin. Earth-Science Reviews, 198, 102903. https://doi.org/10.1016/j. earscirev.2019.102903

Mora, A.; Gaona, T.; Kley, J.; Montoya, D.; Parra, M.; Quiroz, L.I.; Reyes, G.; Strecker, M.R. (2009). The role of inherited extensional fault segmentation and linkage in contractional orogenesis: A reconstruction of lower cretaceous inverted rift basins in the Eastern Cordillera of Colombia. Basin Research, 21(1), 111-137. https://doi. $\operatorname{org} / 10.1111 / \mathrm{j} .1365-2117.2008 .00367 . x$

Moreno, C.J.; Horton, B.K.; Caballero, V.; Mora, A.; Parra, M.; Sierra, J. (2011). Depositional and provenance record of the Paleogene transition from foreland to hinterland basin evolution during Andean orogenesis, northern Middle Magdalena Valley Basin, Colombia. Journal of South American Earth Sciences, 32(3), 246-263. https://doi.org/10.1016/j.jsames.2011.03.018

Morrone, C.; De Rosa, R.; Le Pera, E.; Marsaglia, K.M. (2017). Provenance of volcaniclastic beach sand in a magmatic-arc setting: an example from Lipari island (Aeolian archipelago, Tyrrhenian Sea). Geological Magazine, 154(4), 804-828. https://doi.org/10.1017/S001675681600042X

Murray, R.W. (1994). Chemical criteria to identify the depositional environment of chert: general principles and applications. Sedimentary Geology, 90(3-4), 213-232. https://doi.org/10.1016/00370738(94)90039-6

Murray, K.E.; Braun, J.; Reiners, P.W. (2018). Toward robust interpretation of lowtemperature thermochronometers in magmatic terranes. Geochemistry, Geophysics, Geosystems, 19(10), 3739-3763. https://doi. org/10.1029/2018GC007595

Naranjo, A.; Horner, J.; Jahoda, R.; Diamond, L.W.; Castro, A.; Uribe, A.; Perez, C.; Paz, H.; Mejia, C.; Weil, J. (2018). La Colosa Au porphyry deposit, Colombia: Mineralization styles, structural controls, and age constraints. Economic Geology, 113(3), 553-578. https://doi.org/10.5382/ econgeo.2018.4562

Nie, J.; Horton, B.K.; Mora, A.; Saylor, J.E.; Housh, T.B.; Rubiano, J.; Naranjo, J. (2010). Tracking exhumation of Andean ranges bounding the Middle Magdalena Valley Basin, Colombia. Geology, 38(5), 451-454. https://doi.org/10.1130/ G30775.1

Nie, J.; Horton, B.K.; Saylor, J.E.; Mora, A.; Mange, M.; Garzione, C.N.; Basu, A.; Moreno, C. J.; Caballero, V.; Parra, M. (2012). Integrated provenance analysis of a convergent retroarc foreland system: U-Pb ages, heavy minerals, $\mathrm{Nd}$ isotopes, and sandstone compositions of the Middle Magdalena Valley basin, northern 
Andes, Colombia. Earth-Science Reviews, 110(1-4), 111-126. https://doi.org/10.1016/j. earscirev.2011.11.002

Nivia, A.; Marriner, G.F.; Kerr, A.C.; Tarney, J. (2006). The Quebradagrande Complex: A Lower Cretaceous ensialic marginal basin in the Central Cordillera of the Colombian Andes. Journal of South American Earth Sciences, 21(4), 423-436. https://doi.org/10.1016/j.jsames.2006.07.002

Nivia, A. (2001). Memoria Explicativa mapa geológico del Departamento del Valle del Cauca $(1: 250.000)$. INGEOMINAS.

Ordóñez-Carmona, O.; Pimentel, M.M. (2001). Consideraciones geocronológicas e isotópicas del Batolito Antioqueño. Revista de la Academia Colombiana de Ciencias Exactas, Físicas y Naturales, 25(94), 27-35.

Pardo-Trujillo, A.; Cardona, A.; Giraldo, A.S.; León, S.; Vallejo, D.F.; Trejos-Tamayo, R.; Plata, A.; Ceballos, J.; Echeverri, S.; Barbosa-Espitia, A.; Slattery, J.; Salazar-Ríos, A.; Botello, G.E.; Celis, S.A.; Osorio-Granada, E.; GiraldoVillegas, C.A. (2020). Sedimentary record of the Cretaceous-Paleocene arc-continent collision in the northwestern Colombian Andes: Insights from stratigraphic and provenance constraints. Sedimentary Geology, 401, 105627. https://doi. org/10.1016/j.sedgeo.2020.105627

Pindell, J.L.; Kennan, L. (2009). Tectonic evolution of the Gulf of Mexico, Caribbean and northern South America in the mantle reference frame: an update. Geological Society, London, Special Publications, 328, 1-55. https://doi.org/10.1144/ SP328.1

Pindell, J.L.; Higgs, R.; Dewey, J.F. (1998). Cenozoic palinspastic reconstruction, paleogeographic evolution and hydrocarbon setting of the northern margin of South America. In: J.L. Pindell; C.L. Drake (eds.). Paleogeographic evolution and non-glacial eustasy, northern South America (pp. 45-85). vol. 58. SEPM Society for Sedimentary Geology. https://doi.org/10.2110/pec.98.58.0045

Pindell, J.L.; Kennan, L.; Maresch, W.V.; Stanek, K.P.; Draper, G.; Higgs, R. (2005). Plate-kinematics and crustal dynamics of circum-Caribbean arccontinent interactions: Tectonic controls on basin development in Proto-Caribbean margins. In: H.G.A. Lallemant; V. Sisson (eds.). CaribbeanSouth American plate interactions, Venezuela (pp. 7-52). Vol. 394. GSA Special Papers. https://doi. org/10.1130/0-8137-2394-9.7

Remy, R.R. (1994). Porosity reduction and major controls on diagenesis of Cretaceous-Paleocene volcaniclastic and arkosic sandstone, Middle Park Basin, Colorado. Journal of Sedimentary Research, 64(4a), 797-806. https://doi.org/10.1306/ D4267EC9-2B26-11D7-8648000102C1865D

Restrepo-Moreno, S.A.; Foster, D.A.; Stockli, D.F.; Parra-Sánchez, L.N. (2009). Long-term erosion and exhumation of the "Altiplano Antioqueño", Northern Andes (Colombia) from apatite (U$\mathrm{Th}) / \mathrm{He}$ thermochronology. Earth and Planetary Science Letters, 278(1-2), 1-12. https://doi. org/10.1016/j.eps1.2008.09.037

Reyes-Harker, A.; Ruiz-Valdivieso, C.F.; Mora, A.; Ramírez-Arias, J.C.; Rodríguez, G.; De la Parra, F.; Caballero, V.; Parra, M.; Moreno, N.; Horton, B.K.; Saylor, J.E.; Silva, A.; Valencia, V.; Stockli, D.; Blanco, V. (2015). Cenozoic paleogeography of the Andean foreland and retroarc hinterland of Colombia. AAPG Bulletin, 99(8), 1407-1453. https://doi.org/10.1306/06181411110

Rodríguez, G.; Arango, M.I. (2013). Formación Barroso: Arco Volcánico Toleítico y Diabasas de San José de Urama: Un Prisma Acrecionario T-MORB en el Segmento Norte de la Cordillera Occidental de Colombia. Boletín Ciencias de la Tierra, 33, 17-38.

Rodríguez, G.; Cetina, L.M. (2016). Caracterización petrográfica y química de rocas de corteza oceánica del Complejo Quebradagrande y comparación con rocas de la unidad Diabasas de San José de Urama. Boletín de Geología, 38(3), 15-29. https:// doi.org/10.18273/revbol.v38n3-2016001

Rodríguez-García, G.; Celada-Arango, C.M. (2018). Basaltos de San Pablo: un bloque de un arco de islas en el norte de la cordillera Central de Colombia. Caracterización petrográfica y química. Boletín de Geología, 40(2), 69-85. https://doi.org/10.18273/revbol.v40n2-2018004

Rodríguez-García, G.; Correa-Martínez, A.M.; Zapata-Villada, J.P.; Obando-Erazo, G. (2019). 
Fragments of a Permian arc on the western margin of the Neoproterozoic basement of Colombia. In: J. Gómez; D. Mateus-Zabala (Eds.). The Geology of Colombia (pp. 293-335). Vol. 1, Chapter 10. Servicio Geológico Colombiano. https://doi. org/10.32685/pub.esp.35.2019.10

Rubatto, D. (2002). Zircon trace element geochemistry: partitioning with garnet and the link between $\mathrm{U}-\mathrm{Pb}$ ages and metamorphism. Chemical Geology, 184(1-2), 123-138. https://doi.org/10.1016/ S0009-2541(01)00355-2

Sarmiento-Rojas, L.F.; Van Wess, J.D.; Cloetingh, S. (2006). Mesozoic transtensional basin history of the Eastern Cordillera, Colombian Andes: inferences from tectonic models. Journal of South American Earth Sciences, 21, 383-411. https:// doi.org/10.1016/j.jsames.2006.07.003

Smyth, H.R.; Hall, R.; Nichols, G.J. (2008). Significant volcanic contribution to some quartzrich sandstones, East Java, Indonesia. Journal of Sedimentary Research, 78(5), 335-356. https:// doi.org/10.2110/jsr.2008.039

Spikings, R.; Cochrane, R.; Villagómez, D.; Van der Lelij, R.; Vallejo, C.; Winkler, W.; Beate, B. (2015). The geological history of northwestern South America: from Pangaea to the early collision of the Caribbean Large Igneous Province (290 - 75 Ma). Gondwana Research, 27(1), 95139. https://doi.org/10.1016/j.gr.2014.06.004

Spikings, R.; Paul, A.N. (2019). The Permian - Triassic History of Magmatic Rocks of the Northern Andes (Colombia and Ecuador): Supercontinent Assembly and Disassembly. In: J. Gómez; A.O. Pinilla-Pachon (eds.). The Geology of Colombia (pp. 1-43). Vol. 2, Chapter 1. Servicio Geológico Colombiano.https://doi.org/10.32685/pub. esp.36.2019.01

Spencer, C.J.; Kirkland, C.L.; Taylor, R.J. (2016). Strategies towards statistically robust interpretations of in situ $\mathrm{U}-\mathrm{Pb}$ zircon geochronology. Geoscience Frontiers, 7(4), 581589. https://doi.org/10.1016/j.gsf.2015.11.006

Suttner, L.J.; Basu, A.; Mack, G.H. (1981). Climate and the origin of quartz arenites. Journal of Sedimentary Research, 51(4), 1235-1246.
https://doi.org/10.1306/212F7E73-2B24-11D7$8648000102 \mathrm{C} 1865 \mathrm{D}$

Tamayo, J.; Correa, V. (2010). Petrografía y datación de circones detríticos en las facies cuarzosas del complejo Quebradagrande (Cretácico Inferior) de la Cordillera Central. Tesis, Universidad de Caldas, Manizales, Colombia.

Tamura, Y.; Tatsumi, Y.; Zhao, D.; Kido, Y.; Shukuno, H. (2002). Hot fingers in the mantle wedge: new insights into magma genesis in subduction zones. Earth and Planetary Science Letters, 197(12), 105-116. https://doi.org/10.1016/S0012$821 \mathrm{X}(02) 00465-\mathrm{X}$

Tchegliakova, N. (1996). Registro de las biozonas de foraminíferos planctónicos Gansserina gansseri y Abathomphalus mayaroensis (Maastrichtiano Medio y Superior) en el extremo meridional del Valle Medio del Magdalena (Colombia, Sur América). Geología Colombiana, 20, 67-80.

Terraza-Melo, M. (2012). Estratigrafía y ambientes de depósito de la arenisca de Chiquinquirá en los alrededores de la localidad tipo. Boletín de Geología, 34(2), 55-72.

Toussaint, J.F.; Restrepo, J.J. (1994). The Colombian Andes during Cretaceous times. In: J.A. Salfity (Ed.). Cretaceous tectonics of the Andes (pp. 61-100). Vieweg+Teubner Verlag, Wiesbaden. https://doi.org/10.1007/978-3-322-85472-8_2

Van der Lelij, R.; Spikings, R.; Ulianov, A.; Chiaradia, M.; Mora, A. (2016). Palaeozoic to Early Jurassic history of the northwestern corner of Gondwana, and implications for the evolution of the Iapetus, Rheic and Pacific Oceans. Gondwana Research, 31, 271-294. https://doi.org/10.1016/j. gr.2015.01.011

Villagómez, D. (2010). Thermochronology, geochronology and geochemistry of the Western and Central cordilleras and Sierra Nevada de Santa Marta, Colombia: The tectonic evolution of NW South America. PhD. Thesis, Université de Genève, Switzerland.

Villagómez, D.; Spikings, R. (2013). Thermochronology and tectonics of the Central and Western Cordilleras of Colombia: Early 
Cretaceous-Tertiary evolution of the Northern Andes. Lithos, 160-161, 228-249. https://doi. org/10.1016/j.lithos.2012.12.008

Villagómez, D.; Spikings, R.; Magna, T.; Kammer, A.; Winkler, W.; Beltrán, A. (2011). Geochronology, geochemistry and tectonic evolution of the Western and Central cordilleras of Colombia. Lithos, 125(3-4), 875-896. https://doi.org/10.1016/j. lithos.2011.05.003

Villamil, T. (1999). Campanian-Miocene tectonostratigraphy, depocenter evolution and basin development of Colombia and western Venezuela. Palaeogeography, Palaeoclimatology, Palaeoecology, 153(1-4), 239-275. https://doi. org/10.1016/S0031-0182(99)00075-9

Villamil, T.; Arango, C. (1998). Integrated stratigraphy of latest Cenomanian and early Turonian facies of Colombia. In: J.L. Pindell; C.L. Drake (eds.). Paleogeographic evolution and non-glacial eustasy, northern South America (pp. 129-159). vol. 58. SEPM Society for Sedimentary Geology.

Weber, M.; Gómez-Tapias, J.; Cardona, A.; Duarte, E.; Pardo-Trujillo, A.; Valencia, V. (2015). Geochemistry of the Santa Fé Batholith and Buriticá Tonalite in NW Colombia - Evidence of subduction initiation beneath the Colombian Caribbean Plateau. Journal of South American Earth Sciences, 62, 257-274. https://doi. org/10.1016/j.jsames.2015.04.002

Young, S.W. (1976). Petrographic textures of detrital polycrystalline quartz as an aid to interpreting crystalline source rocks. Journal of Sedimentary Research, 46(3), 595-603. https://doi.org/10.1306/212F6FFA-2B24-11D7$8648000102 \mathrm{C} 1865 \mathrm{D}$

Zapata, S.; Cardona, A.; Montes, C.; Valencia, V.; Vervoort, J.D.; Reiners, P.W. (2014). Provenance of the Eocene Soebi Blanco formation, Bonaire, Leeward Antilles: Correlations with postEocene tectonic evolution of northern South America. Journal of South American Earth Sciences, 52, 179-193. https://doi.org/10.1016/j. jsames.2014.02.009

Zapata, S.; Cardona, A.; Jaramillo, J.S.; Patiño, A.; Valencia, V.; León, S.; Mejía, D.; Pardo-Trujillo, A.; Castañeda, J.P. (2019). Cretaceous extensional and compressional tectonics in the Northwestern Andes, prior to the collision with the Caribbean oceanic plateau. Gondwana Research, 66, 207226. https://doi.org/10.1016/j.gr.2018.10.008

Zapata, S.; Patiño, A.; Cardona, A.; Parra, M.; Valencia, V.; Reiners, P.; Oboh-Ikuenobe, F.; Genezini, F. (2020). Bedrock and detrital zircon thermochronology to unravel exhumation histories of accreted tectonic blocks: An example from the Western Colombian Andes. Journal of South American Earth Sciences, 103. https://doi. org/10.1016/j.jsames.2020.102715

Zapata-Villada, J.P.; Restrepo, J.J.; CardonaMolina, A.; Martens, U. (2017). Geoquímica y geocronología de las rocas volcánicas básicas y el Gabro de Altamira, Cordillera Occidental (Colombia): Registro de ambientes de Plateau y arco oceánico superpuestos durante el Cretácico. Boletín de Geología, 39(2), 13-30. https://doi. org/10.18273/revbol.v39n2-2017001

Zimmermann, S.; Hall, R. (2016). Provenance of Triassic and Jurassic sandstones in the Banda Arc: Petrography, heavy minerals and zircon geochronology. Gondwana Research, 37, 1-19. https://doi.org/10.1016/j.gr.2016.06.001

Trabajo recibido: diciembre 06 de 2019

Trabajo aceptado: agosto 31 de 2020 